Published in final edited form as:

Jpn J Ophthalmol. 2009 July ; 53(4): 352-367. doi:10.1007/s10384-009-0688-1.

\title{
Magnetic Resonance Imaging of the Retina
}

\author{
Timothy Q. Duong ${ }^{1,2,3}$ and Eric R. Muir ${ }^{1,4}$ \\ ${ }^{1}$ Research Imaging Center, Departments of Ophthalmology, Radiology, and Physiology, University \\ of Texas Health Science Center, San Antonio, TX, USA \\ ${ }^{2}$ South Texas Veterans Health Care System, San Antonio, TX, USA \\ ${ }^{3}$ Southwest National Primate Research Center, San Antonio, TX, USA \\ ${ }^{4}$ Graduate Program in Biomedical Engineering, Georgia Institute of Technology, Atlanta, GA, USA
}

\begin{abstract}
This paper reviews recent developments in high-resolution magnetic resonance imaging (MRI) and its application to image anatomy, physiology, and function in the retina of animals. It describes technical issues and solutions in performing retinal MRI, anatomical MRI, blood oxygenation leveldependent functional MRI (fMRI), and blood-flow MRI both of normal retinas and of retinal degeneration. MRI offers unique advantages over existing retinal imaging techniques, including the ability to image multiple layers without depth limitation and to provide multiple clinically relevant data in a single setting. Retinal MRI has the potential to complement existing retinal imaging techniques.
\end{abstract}

\section{Keywords}

blood flow; blood oxygenation level-dependent (BOLD); fMRI; oxygenation; retinal diseases

\section{Background}

\section{Retinal Anatomy and Physiology}

Vision begins at the retina, where light is converted into neurochemical and electrical signals. The neural retina is made up of multiple layers (Fig. 1). ${ }^{1-3}$ Light incident on the outer segment (OS) of the photoreceptors initiates the signal cascade. The neurochemical and electrical signals propagate backward (toward the vitreous) to the inner segment of the photoreceptors, the outer nuclear layer (ONL), the outer plexiform layer (OPL), the inner nuclear layer (INL), the inner plexiform layer (IPL), and the ganglion cell layer (GCL). The signals are transmitted to the fiber nerve layer and the optic nerve. The thickness of the mammalian neural retina, excluding the choroid, is about $200-250 \mu \mathrm{m}$, and is of similar thickness in different species regardless of eye size. ${ }^{2,3}$

The retina is supported by two separate blood supplies, the retinal and choroidal vessels. The retinal vasculature is mainly localized in the GCL, but projects capillaries into the INL, IPL, and OPL. ${ }^{1,4,5}$ The choroidal vasculature is located beneath the photoreceptor layer, between the sclera and retinal pigment epithelium, a thin layer of epithelial cells at the base of the photoreceptor OS. Choroidal vessels do not extend into the photoreceptor layers [ONL, inner

\footnotetext{
(C) Japanese Ophthalmological Society 2009

Correspondence and reprint requests to: Timothy Q. Duong, Research Imaging Center, 8403 Floyd Curl Dr., San Antonio, TX 78229, USA duongt@uthscsa.edu.
} 
segment (IS), OS], which are in fact avascular. These layers therefore rely on diffusion for oxygen delivery, primarily from the choroidal vessels, and transport of metabolites across the retinal pigment epithelium. ${ }^{1,4,5}$ The thickness of the choroid is reported to be $25-45 \mu \mathrm{m}$ in rats. ${ }^{6}$ Importantly, the retinal and choroidal blood flow are regulated very differently. Basal choroidal blood flow is much higher than retinal blood flow, which is similar to cerebral blood flow. Choroidal vessels are less responsive to many blood-flow modulating factors compared with retinal vessels, which, similar to cerebral blood-flow regulation, respond robustly to many blood-flow modulating factors. $1,4,5,7,8$

\section{Optical Imaging}

Optically based imaging techniques have been widely utilized to study the anatomy and physiology of the retina. Methods for imaging retinal anatomy include fundus photography, optical coherence tomography, ${ }^{9}$ and scanning laser ophthalmoscopy. With adaptive optics, spatial resolution can be improved so that single cone and rod cells can be visualized. ${ }^{10}$ Methods to image blood flow include fluorescein angiography, ${ }_{11}$ indocyanine green angiography, ${ }^{12}$ laser Doppler velocimetry and flowmetry, ${ }^{13,14}$ laser speckle imaging, ${ }^{15,16}$ and intrinsic optical imaging. ${ }^{17-21}$ These techniques have been used to study both blood velocity and blood flow in large vessels and relative blood flow and oxygenation in tissues.

Optical techniques, with the exception of optical coherence tomography, are depth limited. Most optical signals come from the retinal surface with unknown extent of signal contamination from deeper layers. Optical techniques may be constrained to a small field of view and may not be used in instances of disease-induced opacity of the vitreous humor, cornea, or lens. Moreover, blood flow and blood velocity optical measurements are limited to large surface vessels, which may not reflect local tissue perfusion. Choroidal blood flow usually cannot easily be viewed with optics because the choroid vessels are hidden behind the retinal pigment epithelium. Nonetheless, optical imaging techniques provide important and clinically relevant information and are widely utilized in the clinical settings.

\section{Magnetic Resonance Imaging}

Magnetic resonance imaging (MRI) can provide relatively high-resolution anatomical, physiological, and functional images noninvasively and in a single setting. MRI also has no depth limitations and offers a large field of view. To date, MRI is arguably the method of choice for noninvasive anatomical imaging of most organs since it provides exquisite soft-tissue contrast and structural details for clinical diagnosis. In addition, blood flow, relative blood oxygenation, and function can also be imaged. Anatomical, blood-flow, vascular oxygenation, and functional MRI (fMRI) techniques are briefly described below.

Anatomical contrast in MRI arises from differences in spin density, spin-lattice relaxation time $\left(\mathrm{T}_{1}\right)$, spin-spin relaxation time $\left(\mathrm{T}_{2}\right)$, and the apparent diffusion coefficient (ADC) of water in tissue. These tissue-specific MRI parameters vary depending on properties of the local tissue environment, including water content, cellular structure, macromolecule content, and ion concentrations. Many diseases alter these biophysical parameters, resulting in visible changes in image contrasts. Moreover, alterations of these contrasts are often detectable in the early stages before clinical symptoms occur, providing opportunities for early detection.

Blood flow, an important physiological parameter, can be quantitatively imaged using MRI. This can be done using an exogenous intravenous contrast agent (dynamic susceptibility contrast) or by magnetically labeling blood noninvasively to provide endogenous contrast [arterial spin-labeling (ASL)]. ${ }^{22}$ These blood-flow imaging methods ${ }^{23-28}$ are widely used to measure quantitative blood flow in the brain and have been cross-validated with autoradiography ${ }^{29}$ and positron emission tomography. ${ }^{30,31}$ Dynamic susceptibility contrast 
MRI, which requires the injection of a contrast agent, has a higher signal-to-noise ratio (SNR). However, it can be performed only once because of the long intravascular half-life of the contrast agent. ASL techniques, on the other hand, are totally noninvasive, and the labeled water has a short half-life ( $\sim$ blood $\mathrm{T}_{1}$ ) making it possible to perform repeated measurements that can be used to augment spatial resolution and the SNR, and to monitor blood flow in real time. $^{22}$

Relative blood oxygenation can also be imaged using the blood oxygenation level-dependent (BOLD) technique. ${ }^{32}$ BOLD MRI detects differences in magnetic resonance signal intensity that arise from changes in oxygen saturation of hemoglobin during brain activation. While oxyhemoglobin is diamagnetic, deoxyhemoglobin is paramagnetic and thus introduces intravoxel magnetic field inhomogeneity, which alters the magnetic resonance signal. Susceptibility-sensitized MRI images can thus show changes in regional deoxyhemoglobin content. A local reduction in deoxyhemoglobin concentration will increase the BOLD signal, while an increase in deoxyhemoglobin will decrease the BOLD signal.

In the brain, when a specific region is activated by a specific stimulation (such as visual stimuli), local blood flow increases to compensate for the increased metabolic activity and oxygen consumption in the region. Such blood flow increases boost oxygen delivery in excess of the increased oxygen consumption associated with increased neural activities. Local oxygen saturation therefore increases, and deoxyhemoglobin concentration decreases. Techniques that can measure blood flow and blood oxygenation can thus noninvasively image brain functions. These are referred to as functional MRI (fMRI) techniques.

The most commonly used fMRI method is BOLD fMRI, which has revolutionized mapping of brain functions, ranging from perception to cognition. ${ }^{32-35}$ Another common fMRI method is based on dynamically measuring blood-flow changes in response to stimuli. Blood-flow fMRI can be made more sensitive to blood flow in smaller vessels, which better reflect local tissue perfusion, avoiding contamination from large draining veins, which are prominent in typical BOLD fMRI. Moreover, blood-flow fMRI is easier to interpret because it measures a single physiological parameter, in contrast to BOLD fMRI, which is affected by multiple physiological parameters, such as blood flow, blood volume, and blood oxygenation. However, blood-flow fMRI has lower temporal resolution and poorer sensitivity per unit time owing to a much lower SNR compared to BOLD fMRI. ${ }^{36}$

Neurovascular coupling in the brain has been studied with fMRI techniques performed during physiologic challenges, such as hyperoxia, hypercapnia, and breath hold. ${ }^{37-40}$ These stimuli alter cerebral blood flow and oxygenation without changing neural activity or oxygen consumption. The integrity of neurovascular coupling, independent of changes in neural activity, can be studied through these methods, providing valuable information.

The spatial resolution of MRI is low relative to optical imaging techniques. With rapid improvements in MRI technology, the spatial and temporal resolutions of MRI have sufficiently advanced to allow anatomical and functional imaging of cortical layers and the columnar structure in the brain. ${ }^{41-46}$ Moreover, a number of recent reports explore the use of MRI to study laminar-specific anatomy, physiology, and function in the retina. ${ }^{6,47-53}$ This paper reviews the recent developments of high-resolution MRI and its novel applications to image anatomy, physiology, and function of the retina in animals. First, technical and animal issues and solutions are discussed. Anatomical MRI, BOLD fMRI, and blood-flow MRI of normal retinas are described. Finally, the application of these retinal MRI techniques to the investigation of retinal degeneration in animal models is presented. MRI offers some unique advantages over other existing retinal imaging techniques, including the ability to image multiple layers without depth limitation and to acquire anatomical and physiological data in a 
single setting. These MRI approaches have the potential to complement optically based imaging techniques.

\section{Technical Considerations for High-Resolution MRI of the Retina}

\section{In Vivo Animal Issues}

In contrast to many optically based imaging techniques, which have remarkable temporal resolution, MRI takes on the order of seconds or minutes to acquire an image. Multiple repetitions are needed to increase the SNR for very high resolution imaging, resulting in a significantly longer acquisition time (several minutes). Thus, eliminating eye movement is critical for high-resolution MRI, particularly during prolonged experiments entailing multiple measurements. Duong et al. ${ }^{53}$ observed that, unlike the brain where the skull can be robustly immobilized, the eye drifts slightly, even under deep isoflurane (1.1\%-3\%). The combination of $1.1 \%$ isoflurane and pancuronium bromide paralytic eliminates eye movement and yields stable anatomical and fMRI measurements of the retina for prolonged imaging studies, ${ }^{6}$ and were employed in most studies described below. Eye drift was independently confirmed by optical imaging of the corneal surface. Quantitative analysis of the optical imaging data showed that the displacement per unit time with the combination of $1.1 \%$ isoflurane and pancuronium bromide is one-tenth that with $1.1 \%$ isoflurane alone (Fig. 2). Stable animal physiological parameters (such as heart rate, respiration rate, end-tidal $\mathrm{CO}_{2}$, blood gases, and body temperature) are also critical to elicit robust fMRI responses. Isoflurane is chosen over injectable anesthetics because gas anesthetics are readily adjustable and can be maintained at a stable level over an extended period. Effects of eye movement under other anesthetics are currently being investigated.

\section{Hardware Issues}

Layer-specific MRI of the retina requires very high spatial resolution. Spatial resolutions of $25 \times 25 \mu \mathrm{m}$ have been targeted for anatomical MRI using conventional gradient-echo imaging, and $90 \times 90 \mu \mathrm{m}$ for physiological and functional MRI using echo-planar imaging (EPI) acquisition. High-resolution retinal MRI is susceptible to hardware-related instability because (1) high-resolution MRI pulse sequences are more demanding on the magnetic field gradients, which can lead to temperature-dependent frequency and/or phase drifts, resulting in displacement in the image space; (2) the smaller pixel size at high spatial resolution can make displacement more apparent; (3) the thin retina is surrounded by the sclera and vitreous, both of which have very different MRI signal intensities than the retina, so misregistration errors can have quite significant impacts; and (4) some MRI techniques such as blood-flow MRI, time-series BOLD fMRI, and blood-flow fMRI are more susceptible to motion between image acquisitions. Careful consideration of hardware-related issues will result in more reliable and temporally stable layer-specific MRI of the retina.

To address these issues, phantom studies have been performed to distinguish hardware-related instability from animal-related instability. ${ }^{53}$ Fastening the animal holder tightly at both ends of the magnetic field gradient eliminates minor holder displacement. Second-order (particularly Z2) shims are avoided because they have been observed to cause significant spatial drift when imaging phantoms. This is likely because second-order shims require several minutes to hours to reach a steady state, depending on shim current. Third-order shims have not been explored or used. FASTMAP shimming ${ }^{54}$ and custom optimization of eddy-current compensation for specific EPI parameters have also been found to be helpful because the retina is located in a region of large magnetic field inhomogeneity.

Despite these improvements, displacement along the phase-encode direction in time-series acquisition has been observed in conventional gradient-echo MRI of a phantom at $25 \times 25$ 
$\mu \mathrm{m}$ (Fig. 3). ${ }^{53}$ The underlying cause was determined to be temperature-dependent $B_{0}$ drift due to the high demand made of the magnetic field gradients, a widely recognized problem both in EPI fMRI ${ }^{55}$ and in spectroscopy. ${ }^{54}$ Such $\mathrm{B}_{\mathrm{O}}$ drift, which results in spatial displacement, is more acute at high spatial resolution. $\mathrm{B}_{\mathrm{o}}$ drift was independently confirmed using ${ }^{1} \mathrm{H}_{2} \mathrm{O}$ localization spectroscopy (data not shown). Phase correction successfully eliminates such displacement errors. ${ }^{53}$

Similar displacement along the phase-encode direction was also observed in vivo in conventional gradient-echo anatomical imaging at $25 \times 25 \mu \mathrm{m}$ (Fig. 4) and EPI at $90 \times 90$ $\mu \mathrm{m}$. Phase correction successfully eliminates these displacement errors. ${ }^{53}$ Phase correction also improves temporal stability of the fMRI as quantified by the standard deviation of the temporal signal fluctuation over the mean signal intensity (data not shown). On the other hand, no significant displacement has been detected in the brain at typical $400 \times 400 \mu \mathrm{m}$ spatial resolutions for rats under $1.1 \%$ isoflurane and without paralysis.

In sum, the following suggestions are made to facilitate the technical aspects of high-resolution retinal MRI in animals: (1) Systemic paralysis is preferred, especially for long experiments, because even under systemic isoflurane anesthesia the eye tends to drift slightly, unlike the brain, for which the skull can be robustly immobilized. (2) Fastening the animal holder at both ends of the magnetic field gradient is helpful. Alternatively, suspending the animal holder to avoid contact with the gradient could be explored. (3) Second-order shims, which have a long settling time constant, should be avoided unless it can be verified that they do not cause $\mathrm{B}_{\mathrm{o}}$ drifts. (4) Fine-tuning eddy-current compensation for EPI parameters is helpful because the retina is located in a region of spatially varying magnetic susceptibility. (5) Despite the above improvements, appreciable $\mathrm{B}_{\mathrm{o}}$ field drift can still be detected, and it causes significant displacement errors up to a few pixels over a few minutes. Displacement errors are generally more severe in EPI than in conventional gradient-echo acquisition. Such displacement errors result in blurring, erroneous blood-flow calculations, and reduced fMRI detection sensitivity. (6) Coregistration and phase correction are effective in mitigating displacement errors, resulting in improved resolving power, blood-flow contrast, and fMRI detection sensitivity. Phase correction generally performs better than coregistration. While these recommendations are specific to high-resolution retinal MRI, some may apply to high-resolution MRI studies in general.

\section{Partial Volume Effect}

As a result of the limited MRI resolution, a partial volume effect (PVE) caused by the thin retina and its curved geometry could be significant in both the in-plane dimension and acrossthe-slice thickness. The in-plane resolution of $90 \times 90 \mu \mathrm{m}$ has 3 pixels across a retinal thickness of $267 \mu \mathrm{m}$, including the choroid. ${ }^{6}$ A $50 \times 50 \mu \mathrm{m}$ resolution has 5 pixels, and a $25 \times 25 \mu \mathrm{m}$ resolution has 11 pixels, across the retina. Assuming a rat eye to have a diameter of $6 \mathrm{~mm}$, the PVE on the imaging slice thickness can be estimated. For the used imaging slice thicknesses of 0.5 or $1.0 \mathrm{~mm}$, PVE is $4 \%$ or $16 \%$ of the total retinal thickness, respectively. ${ }^{6}$ For the larger cat or human eye, a thicker imaging slice can be used.

\section{Signal-to-Noise Ratio}

High-resolution MRI reduces the SNR. High-sensitivity surface coils optimized for imaging the eye, low-noise preamplifiers, high magnetic field scanners, and additional signal averaging (albeit with a longer scan time) can be used to improve the SNR. Ongoing advances in MRI technology, such as improved gradient capability, parallel imaging, and other fast acquisition techniques, are expected to improve spatial and temporal resolution. 


\section{Structural MRI}

\section{$T_{1}, T_{2}$, and Diffusion-Weighted Contrasts}

Layer-specific structural MRI has been reported in rats, ${ }^{6}$ cats, ${ }^{48}$ and mice. ${ }^{56}$ Cheng et al. ${ }^{6}$ detected three anatomical layers in the rat retina at $60 \times 60 \times 500 \mu \mathrm{m}$. They used a T1-weighted FLASH sequence to observe the different layers as alternating bright, dark, and bright bands (Fig. 5A). The vitreous appeared hypointense because of its long $\mathrm{T}_{1}$, and the sclera appeared as a hypointense layer at the back of the retina owing to its low water content and short $\mathrm{T}_{2}$. Similarly, Shen et al..$^{48}$ also observed three anatomical layers in the cat retina at $100 \times 100 \times$ $1500 \mu \mathrm{m}$, again seen as alternating bright, dark, and bright bands, consistent with the findings in the rat (Fig. 5B).

Diffusion-weighted imaging has been performed in the cat retina with diffusion-sensitizing gradients along three principal directions. At $50 \times 100 \times 1500 \mu \mathrm{m}$, this revealed diffusion anisotropy in the cat retina, as can be seen by comparing images with diffusion weighting in different directions (Fig. 6) ${ }^{48}$ The diffusion-weighted images show three alternating bright, dark, bright bands, which localize with the three layers in the basic anatomical images. The intensities of the layers depend upon the direction of the diffusion gradient. Layer-specific values of $T_{2}$ and $A D C$ values have also been measured in the cat retina and are summarized in Table $1 .{ }^{48} \mathrm{~T}_{2}$ and ADC values of the retina are similar to those of the brain but differ markedly from those of the vitreous and sclera. Values of $\mathrm{T}_{2}, \mathrm{~T}_{1}$, and ADC have also been reported in rats $^{57}$ and mice. ${ }^{56}$

\section{Contrast-Enhanced MRI}

Exogenous contrast agents can be used to enhance or alter MRI contrast. Gadolinium diethylenetriamine pentaacetic acid (Gd-DTPA) is a nontoxic MRI contrast agent that shortens water $\mathrm{T}_{1}$ and cannot cross normal blood-brain and blood-retina barriers. The retinal vessels consist of non-fenestrated capillaries, which are impervious to many tracers, including GdDTPA, and tight-junctions between retinal epithelial cells in the choroidal circulation prevent passage of large molecules into the neural retina, including Gd-DTPA. ${ }^{58}$ Therefore, Gd-DTPA enhances the signal in retinal and choroidal vessels, but the avascular photoreceptor layers in the retina do not show any enhancement. Gd-DTPA is commonly used to visualize disruption of the blood-brain barrier in disease, and could also be used to study blood-retina barrier integrity in disease.

Gd-DTPA can be used to locate both the retinal vessels and the choroidal vessels and can aid in the assignment of histological layers of the retina to MRI layers. Intravenous Gd-DTPA has been given to rats ${ }^{6}$ and cats. ${ }^{48}$ In rats, Gd-DTPA enhances the signals in the inner and outer bright bands of the retina (Fig. 7A). This suggests that these two bands correspond to the layers of the retina that contain the retinal and choroidal vessels. The outer band shows more enhancement and is thicker than the inner band, consistent with the larger choroidal blood flow and blood volume compared to the retinal vasculature. ${ }^{1,4,5}$ The dark middle band of the retina is not enhanced by Gd-DTPA, suggesting it corresponds to the avascular photoreceptor layers of the retina. Enhancement is also visible in the extraocular muscles because their blood vessels are permeable to Gd-DTPA, and in the anterior segment of the eye because the ciliary body is permeable to Gd-DTPA. The lens and vitreous do not show any enhancement, consistent with their avascular structures. Gd-DTPA administration in cats gives comparable results (Fig. 7B), confirming the layer-specific anatomical findings in rats.

The assignment of specific histological layers of the retina to MRI layers has been made by careful comparison of the two methods. Figure 8 shows histological sections from rat and cat retinas, with the assigned MRI layers. The GCL, IPL, and INL are assigned to the inner MRI 
band because these layers contain retinal vessels, consistent with Gd-DTPA enhancement in this band. The ONL, IS, and OS are assigned to the middle MRI band because these layers are avascular, consistent with no Gd-DTPA enhancement in this band. The outer MRI band is enhanced by Gd-DTPA and thus has been determined to be the choroid. ${ }^{6}$

\section{Layer Thickness}

To measure thicknesses of specific MRI retinal layers, intensity profiles have been taken perpendicular to the vitreal-retinal boundary, and the profiles from along most of the length of the retina averaged. The thickness of each layer is determined using the half-height of the alternating bands. ${ }^{6}$ Table 2 compares layer-specific thickness measurements from MRI $(n=$ $24)$ and histology ( $n=9$, measurements made near the optic nerve) in the rat retina. Thicknesses of the inner band and the middle band were similar between MRI and histology measurements $(P>0.05, t$-test), but the outer band was significantly thicker when measured by MRI compared with the thickness of the choroid measured from histology $(P<0.05)$. This discrepancy could arise from the PVE as a result of limited MRI spatial resolution, collapse of choroidal vessels after removal of the eyes from the systemic circulation, or histological shrinkage.

Thicknesses in the cat retina have also been measured using MRI and histology. The total retinal thickness of the cat retina including the choroid was measured to be $356 \pm 13 \mu \mathrm{m}$ (mean $\pm \mathrm{SD}$ ) from MRI and $319 \pm 77 \mu \mathrm{m}$ from histology. ${ }^{48}$ This is thicker than the rat retina (MRI, $267 \pm 31 \mu \mathrm{m}$; histology, $205 \pm 11 \mu \mathrm{m}) .{ }^{6}$ The cat retina is thicker because of its tapetum, an additional light-reflecting layer that facilitates night vision. The tapetum is located in the choroid and is vascularized, so its MRI contrast is enhanced by Gd-DTPA. The neural cat retina was $184 \pm 32 \mu \mathrm{m}$, the tapetum was $86 \pm 35 \mu \mathrm{m}$, and the choroid was $82 \pm 14 \mu \mathrm{m}$ measured by histology. ${ }^{48}$ MRI studies of the mouse ${ }^{56}$ and rat ${ }^{59}$ retinas with layer specificity have also been reported with similar total retinal thickness in rodents.

\section{BOLD fMRI}

Cheng et al. ${ }^{6}$ investigated layer-specific neurovascular coupling in the retina using BOLD fMRI in rats in response to physiological stimuli. High-resolution BOLD fMRI was obtained during hyperoxic $\left(100 \% \mathrm{O}_{2}\right)$ and hypercapnic $\left(5 \% \mathrm{CO}_{2}\right.$ with $\left.21 \% \mathrm{O}_{2}\right)$ challenges with air as the baseline. ${ }^{6}$ Data were acquired with spin-echo echo-planar imaging at $90 \times 90 \times 1000 \mu \mathrm{m}$ with diffusion weighting to suppress the over-whelmingly strong but fast-diffusing vitreous signal. Layer-specific BOLD fMRI responses were detected in two bands on the inner and outer edges of the retina (Fig. 9). The two bands, corresponding to the retinal and choroidal vasculature, responded differently to the stimuli, indicative of differences in blood-flow regulation.

As expected, hyperoxia induced a positive BOLD response in both bands, since hyperoxia increases oxygen saturation of the blood when compared to air. The response in the outer/ choroidal band was larger $(12 \pm 2 \%$, mean $\pm \mathrm{SD}, n=8)$ than in the inner/retinal band $(7 \pm 2 \%$, $P<0.01)$. Interestingly, the arteriovenous oxygen difference in the choroid is small when compared to that in the brain, ${ }^{1,4,5}$ so a smaller hyperoxia-induced increase in the BOLD signal in the choroid might be expected. However, the increase in the outer/choroidal band was larger than that in the inner/retinal band, likely because of vasoconstriction of the retinal vessels. Hyperoxia is known to constrict retinal vessels and reduce retinal blood flow by as much as $60 \%,{ }^{13,60}$ compared to a $\sim 13 \%$ decrease in the brain. ${ }^{61}$ This counteracts the increased arterial oxygen saturation with decreased blood flow, which decreases oxygen delivery, but not enough to elicit a negative BOLD response. On the other hand, choroidal vessels constrict by a much smaller extent during hyperoxia, which does not significantly affect choroidal blood flow, leading to a larger BOLD increase in the outer band. ${ }^{13,60}$ 
Hypercapnia also induces positive BOLD changes in the retina, although the layer-specific responses are quite different than those associated with hyperoxia. In hypercapnia, the BOLD increase in the inner/retinal band $(10 \pm 2 \%, n=8)$ is markedly larger than that in the outer/ choroidal band $(1.6 \pm 1 \%, P<0.01)$. This is likely because hypercapnia potently induces vasodilation in retinal vessels but has much less effect in choroidal vessels. ${ }^{5,60}$ Increased blood flow in retinal vasculature results in decreased fractional oxygen extraction and increased capillary and venous oxygen saturation, which increases the BOLD signal relative to air. ${ }^{32}$ Since the choroid undergoes minimal vasodilation, there is little change in blood flow or blood oxygenation, so the BOLD response is very small. The minimal choroidal vasodilation is likely due to unique choroidal physiology or the high basal choroidal blood flow, causing a ceiling effect. ${ }^{39}$

In summary, BOLD fMRI of the retina can detect separate responses in the two vascular layers, enabling investigation of layer-specific retinal physiology, which is difficult to do with optical techniques. The hyperoxic and hypercapnic fMRI results have demonstrated different regulation of the two vascular supplies of the retina, consistent with previous research using oxygen-electrode ${ }^{62}$ and laser Doppler velocimetry. ${ }^{63}$ Since BOLD fMRI is affected by multiple physiological parameters, more direct techniques such as blood-flow fMRI could provide further information to complement the results of BOLD fMRI and provide a better understanding of neurovascular coupling in the retina.

\section{Blood-Flow MRI}

Li et al. ${ }^{49}$ investigated blood flow of the rat retina using MRI. ASL was implemented to measure quantitative basal blood flow and blood-flow fMRI changes during physiological stimulation. Blood-flow MRI in the rat retina was performed using gradient-echo echo-planar imaging at $90 \times 90 \times 1000 \mu \mathrm{m}$. A butterfly neck coil was positioned at the common carotid arteries for magnetic labeling of inflowing blood. The neck and the eye coils were actively decoupled to avoid artifacts, which can otherwise occur. ${ }^{64}$ High-resolution blood-flow fMRI was obtained during hyperoxic $\left(100 \% \mathrm{O}_{2}\right)$ and hypercapnic $\left(5 \% \mathrm{CO}_{2}\right.$ with $\left.21 \% \mathrm{O}_{2}\right)$ challenges with air as the baseline. ${ }^{49}$

Quantitative blood flow was measured by MRI with the rat breathing air to obtain basal blood flow. Blood-flow images $\left(\mathrm{S}_{\mathrm{BF}}\right)$ in milliliters of blood per gram of tissue per minute were calculated pixel-by-pixel using $\mathrm{S}_{\mathrm{BF}}=\lambda / \mathrm{T}_{1}\left[\left(\mathrm{~S}_{\mathrm{NL}}-\mathrm{S}_{\mathrm{L}}\right) /\left(\mathrm{S}_{\mathrm{L}}+(2 \alpha-1) \mathrm{S}_{\mathrm{NL}}\right)\right]{ }^{64}$ where $\mathrm{S}_{\mathrm{NL}}$ is the signal intensity of the nonlabeled images and $S_{L}$ is the signal intensity of the labeled images. $\lambda$, the water tissue-blood partition coefficient, was $0.9,{ }^{65} \mathrm{~T}_{1}$ was $1.7 \mathrm{~s}$ at 7 Tesla, and $\alpha$, the arterial spin-labeling efficiency, was $0.8 .{ }^{64}$ Quantitative basal blood-flow images showed the highest blood flow in the retina and ciliary body. No blood flow was detected in the lens, cornea, or vitreous, consistent with them being avascular (Fig. 10A). ${ }^{49}$ Blood flow averaged over the entire retina was $6.3 \pm 1.0 \mathrm{ml} / \mathrm{g}$ per minute (mean $\pm \mathrm{SD}, n=6$ ) under $1.1 \%$ isoflu-rane. To demonstrate that blood flow was the source of the signals, measurements were repeated after the rats were euthanized in the MRI scanner (Fig. 10B). There was no statistically significant blood flow in the post mortem retina (average, $0.03 \pm 0.01 \mathrm{ml} / \mathrm{g}$ per minute, $n=3$ ),

demonstrating that blood flow was the source of the signal, and not artifacts such as coupling or saturation effects from the labeling coil. Blood flow along the length of the retina was analyzed and found to be relatively constant, except for dipping slightly at the optic nerve head and dropping considerably at the distal edges where the retina terminates. The measured blood flow of the retina was much higher than cerebral blood flow, $\sim 1 \mathrm{ml} / \mathrm{g}$ per minute, ${ }^{39,66}$ under essentially identical experimental conditions. Blood-flow measurements in the retina and brain obtained in the same animals using microsphere techniques ${ }^{67,68}$ have given similar results. Note that the resolution used in this study prevented reliable analysis of blood flow in the two vascular layers within the retina. 
The ASL MRI technique was also used to perform blood-flow fMRI of the rat retina in response to physiological challenges. ${ }^{49}$ Hyperoxia decreased total retinal blood flow by $25 \pm 6 \%(n=$ 6), from $6.3 \pm 1.0$ to $4.8 \pm 0.6 \mathrm{ml} / \mathrm{g}$ per minute (Fig. 10C). This change is a weighted average of the changes in the retinal and choroidal vasculatures. Hyperoxia is reported to decrease retinal blood flow by 30\%-60\% through other techniques, while having little or no effect on choroidal blood flow. ${ }^{13,60}$ Taken together, the measured blood-flow changes by MRI are sensitive enough to detect large decreases in retinal blood flow, although basal blood flow is weighted heavily by the high blood flow in the choroid.

Hypercapnia increased total retinal blood flow by $16 \pm 6 \%(n=6)$, from $6.3 \pm 1.0$ to $7.3 \pm 1.1$ $\mathrm{ml} / \mathrm{g}$ per minute relative to air (Fig. 10D). Hypercapnia has been reported to potently induce vasodilation in retinal vessels while inducing little dilation of choroidal vessels, measured with other techniques. ${ }^{5,60}$ Similar to the hyperoxic results, blood flow measured by MRI is sensitive enough to detect blood-flow increases during hypercapnia, despite the combined retinal and choroidal blood flows. Both the hyperoxic and hyper-capnic results in the retina are similar to cerebral blood-flow responses.

Isoflurane is known to cause dose-dependent vasodilation, which has been well documented in the brain. ${ }^{69}$ The effect of isoflurane on circulation of the retina has been investigated with blood-flow MRI. Blood flow has been measured in rats at two different isoflurane concentrations in air, ${ }^{49}$ demonstrating profound effects on blood flow in the retina. Blood flow in the retina under $1.1 \%$ isoflurane was $6.3 \pm 1.0 \mathrm{ml} / \mathrm{g}$ per minute and increased to $9.3 \pm 2.7$ $\mathrm{ml} / \mathrm{g}$ per minute under $1.5 \%$ isoflurane $(48 \%$ increase, $P<0.05) .{ }^{49}$ For comparison, cerebral blood flow under $1 \%$ isoflurane $(1.27 \pm 0.29 \mathrm{ml} / \mathrm{g}$ per minute $)$ was higher than under awake restrained conditions $(0.86 \pm 0.25 \mathrm{ml} / \mathrm{g}$ per minute $)$ in the same animals. ${ }^{70}$ Also, cerebral blood flow under $1 \%$ isoflurane was lower than under $2 \%$ isoflurane in the same animals. ${ }^{71}$ Isoflurane appears to have similar vasodilatory effects on vessels in the retina as in the brain, but differential effects on retinal and choroidal vessels may exist and remain to be investigated.

In summary, these studies demonstrate that high-resolution MRI can noninvasively image quantitative basal blood flow and blood-flow changes in the retina. MRI has the potential to provide unique information on how blood flow is regulated and how retinal diseases may affect blood flow and the neural tissues they supply. The quantitative measurements of blood-flow MRI should also allow direct comparisons between experimental groups and longitudinal monitoring of disease progression. Unfortunately, the spatial resolution of blood-flow MRI used in rats is insufficient to resolve the two vascular layers, so the measured values are weighted by both.

\section{Functional MRI of Visual Stimulation}

Duong et al. ${ }^{47}$ reported the first use of BOLD fMRI to image visual responses in the cat retina. BOLD fMRI was performed with a gradient-echo echo-planar imaging sequence with an inversion pulse to null the vitreous. Visual stimuli consisting of either drifting or stationary gratings, with identical contrast and luminance relative to dark as the basal condition, were presented to the upper or lower quadrant of the visual field in cats.

As expected, the different locations of the stimuli in the visual field result in spatially distinct changes in the BOLD fMRI signal of the retina. Stimuli presented to the upper half of the visual field stimulate the lower part of the retina, and stimuli presented to the lower half of the visual field stimulate the upper part of the retina (Fig. 11A). Additionally, BOLD fMRI has been demonstrated to have enough sensitivity to detect the difference between drifting and stationary gratings (Fig. 11B) ${ }^{47}$ Positive fMRI signal changes are evoked by both gratings, but drifting gratings induce twice the signal change as stationary gratings. The signal increase due to 
drifting gratings was $2.0 \pm 0.3 \%$ (mean $\pm \mathrm{SD}, n=2$, with four measurements), while stationary gratings gave a $1.0 \pm 0.1 \%$ increase $(P<0.02)$.

As previously discussed, layer-specific BOLD fMRI of the retina during physiological challenges has been demonstrated, and the ability to detect functional changes due to visual stimulation could provide further important information on retinal physiology. Future studies need improved spatial resolution to obtain layer-specific BOLD fMRI in response to visual stimuli, to develop blood-flow fMRI in response to visual stimuli, and to improve temporal resolution.

\section{MRI of Retinal Degeneration}

Retinitis pigmentosa (RP) is a family of retinal diseases associated with progressive photoreceptor degeneration that affects 1.5 million people worldwide. ${ }^{72}$ Other neural and synaptic layers in the retina and the two vascular layers supporting the retina also deteriorate slowly over time. The genetic aspects of the disease are well studied, and many mutations in a number of genes have been implicated. ${ }^{73}$ The Royal College of Surgeons (RCS) rat is an established model of RP with a mutation in the MERTK gene that results in impaired phagocytosis of photoreceptor segments by the retinal pigment epithelium. ${ }^{74-76}$ The genetics of the RCS rat have been well characterized and structural changes studied by histology. ${ }^{75}$, 77,78 Retinal degeneration begins in the RCS rat at approximately 20 days postnatal (P20) and is complete by P90. ${ }^{79}$ The lack of noninvasive imaging techniques has limited the investigation of structure, blood flow, oxygenation, functional hemodynamic responses, and temporal progression of this disease in vivo.

\section{Anatomical MRI}

Anatomical changes in RCS rats were studied using MRI performed before and after retinal degeneration, at ages P16 and P120. ${ }^{6}$ Three layers were visible in the RCS rat retina at P16, the same as in normal retinas, but at P120 only a single layer was visible (Fig. 12).

Administration of intravenous Gd-DTPA enhanced the entire remaining single layer of the retina in the P120 RCS rat, consistent with the loss of the avascular outer nuclear layer and the inner and outer segments. Intensity profiles perpendicular to the retina also showed the absence of a dark middle band and thinning of the P120 RCS retina. Interestingly, the outer band appeared slightly thickened. Histology of the same retinas confirmed the loss of the photoreceptor layers and thinning of the retina. ${ }^{6}$ In place of the photoreceptors and photoreceptor segments, only a thin debris layer was visible in the P120 RCS retina. Table 3 shows the thicknesses of layers measured by MRI and histology for both age groups.

\section{BOLD fMRI}

Disruption of neurovascular coupling in the RCS rat retina has been shown using BOLD fMRI. P120 RCS rats were imaged during hyperoxia and hypercapnia. ${ }^{6}$ BOLD fMRI responses to hyperoxia were detected in both retinal and choroidal vascular layers in P120 RCS rats (inner/ retinal band, $4.2 \pm 2.5 \%$; outer/choroidal band. $8.7 \pm 2.4 \%$, mean $\pm \mathrm{SD}, n=4$ ). These changes were significantly smaller than the control animals (inner/retinal band, $7 \pm 2 \%$; outer/choroidal band, $12 \pm 2 \%, n=8$ ). In response to hypercapnia, BOLD fMRI changes mostly disappeared in P120 RCS rats (inner/retinal band, $-0.02 \pm 6.5 \%$; outer/choroidal band, $0.003 \pm 6 \%, n=4$ ), unlike in the control animals (inner/retinal band, $10 \pm 2 \%$; outer/choroidal band, $1.6 \pm 1 \%, n$ $=8$ ). This response to hypercapnia suggests that no vasocon-striction occurred in either vascular layer in the P120 RCS rat. Since the choroidal vessels mainly supply the photoreceptor layers, which degenerate in the RCS rat, diminished reactivity in the choroid might be expected. The reduced BOLD response in the retinal vascular layer could be secondary to photoreceptor degeneration (i.e., thinning of the inner retina). Perturbed neurovascular coupling has also been 
demonstrated by an abnormal oxygen profile in the RCS rat retina, ${ }^{62}$ and perturbed retinal circulation reported in human RP. ${ }^{80}$ The present findings indicate perturbed hemodynamic coupling and basal blood flow, and if confirmed, could have important implications on the vascular health of the retina during RP, a topic of particular importance for treatments such as retinal prosthetics. ${ }^{81}$

\section{Blood-Flow Measurements}

Li et al. ${ }^{50}$ investigated blood flow of the retina in RCS rats at P90 and P220 using ASL MRI. Representative blood-flow images of a P90 control rat and a P90 RCS rat are depicted in Fig. 13A. There were significant quantitative blood-flow differences between normal and RCS retinas. Figure 13B shows blood-flow profiles drawn perpendicularly across the retina of a control and RCS rat retina. Blood flow in the normal P90 retina was $\sim 5.5 \mathrm{ml} / \mathrm{g}$ per minute. Basal blood flow in the RCS rat retinas at P90 was $\sim 2.6 \mathrm{ml} / \mathrm{g}$ per minute, markedly diminished compared to the age-matched controls. Under basal conditions, control P90 blood flow was significantly higher than P220 $(P<0.05)$, suggesting vascular changes occur due to age in the normal retina. Looking at group-averaged blood flow as a function of distance from the optic nerve head for control and RCS rat retinas at P90, blood flow in the RCS rat retina was largely diminished across the entire retinal length relative to controls.

Changes in blood flow in RCS rat retinas in response to hyperoxia and hypercapnia have also been studied with blood-flow fMRI. ${ }^{50}$ RCS rats and age-matched controls were imaged at P90 and P220. Hyperoxia significantly decreased blood flow in both normal and RCS rat retinas $(P<0.05)$. Absolute hyperoxia-induced blood-flow changes were not statistically different between RCS and controls, but the percent change decreases were significantly larger in RCS rats compared to controls at P90. Hypercapnia significantly increased blood flow in both normal and RCS rat retinas $(P<0.05)$. Absolute hypercapnia-induced blood-flow changes were not statistically different between RCS and controls, but the percent change increases were significantly larger in RCS rats than in controls. Blood-flow absolute changes in RCS retinas were not significantly different than in control retinas for both hyperoxia and hypercapnia, but percent changes were larger in RCS retinas because of the lower basal blood flow in RCS retinas. These results suggest that vascular reactivity may not be perturbed in retinal degeneration. They also suggest caution in interpreting differences in relative functional MRI signals in disease states in which basal blood flow is significantly altered.

\section{Summary and Future Perspectives}

This review summarizes recent development and application of high-resolution anatomical, physiological, and functional MRI of the retina and disease-induced changes in MRI signals associated with retinal degeneration in animal models. MRI reveals the multiple anatomical layers within the retina, the retinal and choroid vascular layers, and the unique differential regulation of hemodynamics of the two vascular layers. With rapid advances in MRI technology, the expansion of MRI applications in the retina is likely.

Currently human retinal MRI may be confounded by eye movement in awake humans and limited spatial resolution of current human scanners. Improvements will be facilitated by trained fixation that would reduce eye movement. As the eye is spherical and eye movement is trackable, postprocessing coregistration is likely to be straightforward. Correction algorithms, such as post k-space reconstruction to discard motion-contaminated k-space lines based on eye-tracking already exist and can be applied. Moreover, with continuing rapid advances in gradient capability, low-noise preamplifiers, more sensitive detectors, and faster acquisition methods (such as parallel imaging to accelerate k-space acquisition), the technical challenges for human retinal MRI can be met. 
Nonetheless, at present MRI should readily serve as a valuable tool to study normal retinal physiology and retinal diseases (such as diabetic retinopathy, glaucoma, and macular degeneration) in animal models. Retinal MRI would enable improved longitudinal staging of a disease, testing of therapeutic interventions, and characterization of disease processes in vivo.

\section{Acknowledgments}

The research projects reported here are supported by the U. S. National Institutes of Health/National Eye Institute (R01 EY014211 and R01 EY018855), Whitaker Foundation (RG-02-0005), and MERIT Awards and a Research Career Development Award from the U. S. Department of Veterans Affairs. We thank Drs. Govind Nair and Tsukasa Nagaoka for their help in acquiring Figure 2 for our use.

\section{References}

1. Kaufman, PL.; Alm, A., editors. Adler's physiology of the eye. Mosby; St Louis: 1992.

2. Bron, AJ.; Tripathi, RC.; Tripathi, BJ. Wolff's anatomy of the eye and orbit. Chapman \& Hall Medical; London: 1997.

3. Buttery RG, Hinrichsen CFL, Weller WL, Haight JR. How thick should a retina be? A comparative study of mammalian species with and without intraretinal vasculature. Vis Res 1991;31:169-187. [PubMed: 2017880]

4. Harris A, Kagemann L, Cioffi GA. Assessment of human ocular hemodynamics. Surv Ophthalmol 1998;42:509-533. [PubMed: 9635901]

5. Bill, A. Circulation in the eye. In: Renkin, EM.; Michel, CC., editors. Handbook of physiology, part 2, in microcirculation. American Physiological Society; Bethesda, MD: 1984. p. 1001-1035.

6. Cheng H, Nair G, Walker TA, et al. Structural and functional MRI reveals multiple retinal layers. Proc Natl Acad Sci U S A 2006;103:17525-17530. [PubMed: 17088544]

7. Alm A, Bill A. Blood flow and oxygen extraction in the cat uvea at normal and high intraocular pressures. Acta Physiol Scand 1970;80:19-28. [PubMed: 5475327]

8. Friedman E, Kopald HH, Smith TR. Retinal and choroidal blood flow determined with krypton 85 in anesthetized animals. Invest Ophthalmol 1964;3:539-547. [PubMed: 14229941]

9. Fujimoto JG, Brezinski ME, Tearney GJ, et al. Optical biopsy and imaging using optical coherence tomography. Nat Med 1995;1:970-972. [PubMed: 7585229]

10. Zawadzki RJ, Jones SM, Olivier SS, et al. Adaptive-optics optical coherence tomography for highresolution and high-speed 3D retinal in vivo imaging. Opt Exp 2005;13:8532-8546.

11. Preussner PR, Richard G, Darrelmann O, Weber J, Kreissig I. Quantitative measurement of retinal blood flow in human beings by application of digital image-processing methods to television fluorescein angiograms. Graefes Arch Clin Exp Ophthalmol 1983;221:110-112. [PubMed: 6689414]

12. Guyer DR, Yannuzzi LA, Slakter JS, Sorenson JA, Orlock S. The status of indocyanine-green videoangiography. Curr Opin Ophthalmol 1993;4:3-6. [PubMed: 10151008]

13. Riva CE, Grunwald JE, Sinclair SH. Laser Doppler velocimetry study of the effect of pure oxygen breathing on retinal blood flow. Invest Ophthalmol Vis Sci 1983;24:47-51. [PubMed: 6826314]

14. Riva CE, Logean E, Falsini B. Visually evoked hemodynamical response and assessment of neurovascular coupling in the optic nerve and retina. Prog Retin Eye Res 2005;24:183-215. [PubMed: 15610973]

15. Cheng H, Duong TQ. Simplified laser-speckle-imaging analysis method and its application to retinal blood flow imaging. Opt Lett 2007;32:2188-2190. [PubMed: 17671579]

16. Cheng H, Yan Y, Duong TQ. Temporal statistical analysis of laser speckle image and its application to retinal blood-flow imaging. Opt Exp 2008;16:10214-10219.

17. Grinvald A, Bonhoeffer T, Vanzetta I, et al. High-resolution functional optical imaging: from the neocortex to the eye. Ophthalmol Clin North Am 2004;17:53-67. [PubMed: 15102513]

18. Tsunoda K, Oguchi Y, Hanazona G, Tanifuji M. Mapping cone- and rod- induced retinal responsiveness in macaque retina by optical imaging. Invest Ophthalmol Vis Sci 2004;45:3820 3826. [PubMed: 15452094] 
19. Hanazono G, Tsunoda K, Shinoda K, Tsubota K, Miyake Y, Tanifuji M. Intrinsic signal imaging in macaque retina reveals different types of flash-induced light reflectance changes of different origins. Invest Ophthalmol Vis Sci 2007;48:2903-2912. [PubMed: 17525227]

20. Hanazono G, Tsunoda K, Kazato Y, Tsubota K, Tanifuji M. Evaluating neural activity of retinal ganglion cells by flash-evoked intrinsic signal imaging in macaque retina. Invest Ophthalmol Vis Sci 2008;49:4655-4663. [PubMed: 18539934]

21. Tsunoda K, Oguchi Y, Hanazono G, Tanifuji M. Mapping cone- and rod-induced retinal responsiveness in macaque retina by optical imaging. Invest Ophthalmol Vis Sci 2004;45:3820 3826. [PubMed: 15452094]

22. Calamante F, Gadian DG, Connelly A. Quantification of perfusion using bolus tracking magnetic resonance imaging in stroke: assumptions, limitations, and potential implications for clinical use. Stroke 2002;33:1146-1151. [PubMed: 11935075]

23. Alsop D, Detre J. Reduced transit-time sensitivity in noninvasive magnetic resonance imaging of human cerebral blood flow. J Cereb Blood Flow Metab 1996;16:1236-1249. [PubMed: 8898697]

24. Wong EC, Buxton RB, Frank LR. Quantitative imaging of perfusion using a single subtraction (QUIPSS and QUIPSSII). Magn Reson Med 1998;39:702-708. [PubMed: 9581600]

25. Wong EC, Buxton RB, Frank LR. A theoretical and experimental comparison of continuous and pulsed arterial spin labeling techniques for quantitative perfusion imaging. Magn Reson Med 1998;40:348-355. [PubMed: 9727936]

26. Detre JA, Zhang W, Roberts DA, et al. Tissue specific perfusion imaging using arterial spin labeling. NMR Biomed 1994;7:75-82. [PubMed: 8068529]

27. Williams DS, Detre JA, Leigh JS, Koretsky AP. Magnetic resonance imaging of perfusion using spin inversion of arterial water. Proc Natl Acad Sci U S A 1992;89:212-216. [PubMed: 1729691]

28. Duong TQ, Silva AC, Lee S-P, Kim S-G. Functional MRI of calcium-dependent synaptic activity: cross correlation with CBF and BOLD measurements. Magn Reson Med 2000;43:383-392. [PubMed: 10725881]

29. Tsekos NV, Zhang F, Merkle H, Nagayama M, Iadecola C, Kim S-G. Quantitative measurements of cerebral blood flow in rats using the FAIR technique: correlation with previous iodoantipyrine autoradiographic studies. Magn Reson Med 1998;39:564-573. [PubMed: 9543418]

30. Zaini MR, Strother SC, Andersen JR, et al. Matching spatial resolution of coregistered PET and 4.0T fMRI brain volumes. Med Phys 1999;26:1559-1567. [PubMed: 10501056]

31. Liu HL, Kochunov P, Hou J, et al. Perfusion-weighted imaging of interictal hypoperfusion in temporal lobe epilepsy using FAIR-HASTE: comparison with H(2)(15)O PET measurements. Magn Reson Med 2001;45:431-435. [PubMed: 11241700]

32. Ogawa S, Lee T-M, Kay AR, Tank DW. Brain magnetic resonance imaging with contrast dependent on blood oxygenation. Proc Natl Acad Sci U S A 1990;87:9868-9872. [PubMed: 2124706]

33. Ogawa S, Tank DW, Menon R, et al. Intrinsic signal changes accompanying sensory stimulation: functional brain mapping with magnetic resonance imaging. Proc Natl Acad Sci U S A 1992;89:5951-5955. [PubMed: 1631079]

34. Kwong K, Hoppel B, Weisskoff R, et al. Regional cerebral tissue oxygenation studied with EPI at clinical field strengths. J Magn Reson Imaging 1992;2:44.

35. Bandettini PA, Wong EC, Hinks RS, Rikofsky RS, Hyde JS. Time course EPI of human brain function during task activation. Magn Reson Med 1992;25:390-397. [PubMed: 1614324]

36. Duong TQ, Kim DS, Ugurbil K, Kim SG. Localized cerebral blood flow response at submillimeter columnar resolution. Proc Natl Acad Sci U S A 2001;98:10904-10909. [PubMed: 11526212]

37. Posse S, Elghahwagi B, Wiese S, Kiselev VG. Effect of graded hypo- and hypercapnia on fMRI contrast in visual cortex: quantification of T2* changes by multiecho EPI. Magn Reson Med 2001;46:264-271. [PubMed: 11477629]

38. Cohen ER, Ugurbil K, Kim S-G. Effect of basal conditions on the magnitude and dynamics of the blood oxygenation level-dependent fMRI response. J Cereb Blood Flow Metab 2002;22:1042-1053. [PubMed: 12218410]

39. Sicard KM, Duong TQ. Effects of hypoxia, hyperoxia and hypercapnia on baseline and stimulusevoked BOLD, CBF and CMRO2 in spontaneously breathing animals. Neuroimage 2005;25:850 858. [PubMed: 15808985] 
40. Duong TQ, Iadacola C, Kim S-G. Effect of hyperoxia, hypercapnia and hypoxia on cerebral interstitial oxygen tension and cerebral blood flow in the rat brain: an 19F/1H study. Magn Reson Med 2001;45:61-70. [PubMed: 11146487]

41. Silva AC, Koretsky AP. Laminar specificity of functional MRI onset times during somatosensory stimulation in rat. Proc Natl Acad Sci U S A 2002;99:15182-15187. [PubMed: 12407177]

42. Goense JB, Logothetis NK. Laminar specificity in monkey V1 using high-resolution SE-fMRI. Magn Reson Imaging 2006;24:381-392. [PubMed: 16677944]

43. Kim D-S, Duong TQ, Kim S-G. High-resolution mapping of iso-orientation columns by fMRI. Nat Neurosci 2000;3:164-169. [PubMed: 10649572]

44. Duong TQ, Kim D-S, Ugurbil K, Kim S-G. Localized blood flow response at sub-millimeter columnar resolution. Proc Natl Acad Sci U S A 2001;98:10904-10909. [PubMed: 11526212]

45. Cheng K, Waggoner RA, Tanaka K. Human ocular dominance columns as revealed by high-field functional magnetic resonance imaging. Neuron 2001;32:359-397. [PubMed: 11684004]

46. Duong TQ, Kim D-S, Ugurbil K, Kim S-G. Spatio-temporal dynamics of the BOLD fMRI signals in cat visual cortex: toward mapping columnar structures using the early negative response. Magn Reson Med 2000;44:231-242. [PubMed: 10918322]

47. Duong TQ, Ngan S-C, Ugurbil K, Kim S-G. Functional magnetic resonance imaging of the retina. Invest Ophthalmol Vis Sci 2002;43:1176-1181. [PubMed: 11923263]

48. Shen Q, Cheng H, Pardue MT, et al. Magnetic resonance imaging of tissue and vascular layers in the cat retina. J Magn Reson Imaging 2006;23:465-472. [PubMed: 16523482]

49. Li Y, Cheng H, Duong TQ. Blood-flow magnetic resonance imaging of the retina. Neuroimage 2008;39:1744-1751. [PubMed: 18063388]

50. Li Y, Cheng H, Shen Q, et al. Blood-flow magnetic resonance imaging of retinal degeneration. Invest Ophthalmol Vis Sci 2009;50:1824-1830. [PubMed: 18952917]

51. Berkowitz BA, Roberts R, Goebel DJ, Luan H. Noninvasive and simultaneous imaging of layerspecific retinal functional adaptation by manganese-enhanced MRI. Invest Ophthalmol Vis Sci 2006;47:2668-2674. [PubMed: 16723485]

52. Duong TQ, Pardue MT, Thule PM, et al. Layer-specific anatomical, physiological and functional MRI of the retina. NMR Biomed 2008;21:978-996. [PubMed: 18792422]

53. Duong TQ, Zhang X, Li Y. Systematic evaluation of hardware and animal stability for high-resolution layer-specific MRI of the retina. J Magn Reson Imaging. 2009 in press.

54. Gruetter R. Automatic, localized in vivo adjustment of all first- and second-order shim coils. Magn Reson Med 1993;29:804-811. [PubMed: 8350724]

55. Kochunov PV, Liu HL, Andrews T, Gao JH, Fox PT, Lancaster JL. A B(0) shift correction method based on edge RMS reduction for EPI fMRI. J Magn Reson Imaging 2000;12:956-959. [PubMed: 11105036]

56. Chen J, Wang Q, Zhang H, et al. In vivo quantification of $\mathrm{T}(1), \mathrm{T}(2)$, and apparent diffusion coefficient in the mouse retina at 11.74T. Magn Reson Med 2008;59:731-738. [PubMed: 18383302]

57. Nair, G.; Shen, Q.; Duong, TQ. T1, T2, and ADC of the rat retina at 7T; Proceedings of the 16th Annual Meeting of the ISMRM; Toronto, Canada. 3-9 May 2008; Abstract 2224

58. Vinores SA. Assessment of blood-retinal barrier integrity. Histol Histopathol 1995;10:141-154. [PubMed: 7756735]

59. Luan H, Roberts R, Sniegowski M, Goebel DJ, Berkowitz BA. Retinal thickness and subnormal retinal oxygenation response in experimental diabetic retinopathy. Invest Ophthalmol Vis Sci 2006;47:320-328. [PubMed: 16384980]

60. Trokel S. Effect of respiratory gases upon choroidal hemodynamics. Arch Ophthalmol 1965;73:838842. [PubMed: 14302519]

61. Kety SS, Schmidt CF. The effects of altered arterial tensions of carbon dioxide and oxygen on cerebral blood flow and cerebral oxygen consumption of normal young men. J Clin Invest 1948;27:484-491.

62. Yu D-Y, Cringle SJ, Su E-N, Yu PK. Intraretinal oxygen levels before and after photoreceptor loss in the RCS rat. Invest Ophthalmol Vis Sci 2000;41:3999-4006. [PubMed: 11053305]

63. Riva CE, Cranstoun SD, Mann RM, Barnes GE. Local choroidal blood flow in the cat by laser Doppler flowmetry. Invest Ophthalmol Vis Sci 1994;35:608-618. [PubMed: 8113011] 
64. Shen Q, Ren H, Cheng H, Fisher M, Duong TQ. Functional, perfusion and diffusion MRI of acute focal ischemic brain injury. J Cereb Blood Flow Metab 2005;25:1265-1279. [PubMed: 15858531]

65. Herscovitch P, Raichle ME. What is the correct value for the brain-blood partition coefficient for water? J Cereb Blood Flow Metab 1985;5:65-69. [PubMed: 3871783]

66. Liu ZM, Schmidt KF, Sicard KM, Duong TQ. Imaging oxygen consumption in forepaw somatosensory stimulation in rats under isoflurane anesthesia. Magn Reson Med 2004;52:277-285. [PubMed: 15282809]

67. Alm A, Bill A. Ocular and optic nerve blood flow at normal and increased intraocular pressures in monkeys (Macaca irus): a study with radioactively labeled microspheres including flow determinations in brain and some other tissues. Exp Eye Res 1973;15:15-29. [PubMed: 4630581]

68. Wang L, Fortune B, Cull G, McElwain KM, Cioffi GA. Microspheres method for ocular blood flow measurement in rats: size and dose optimization. Exp Eye Res 2007;84:108-117. [PubMed: 17069799]

69. Matta BF, Heath KJ, Tipping K, Summors AC. Direct cerebral vasodilatory effects of sevoflurane and isoflurane. Anesthesiology 1999;91:677-680. [PubMed: 10485778]

70. Sicard K, Shen Q, Brevard M, et al. Regional cerebral blood flow and BOLD response in conscious and anesthetized rats under basal and hypercapnic conditions: implications for fMRI studies. J Cereb Blood Flow Metab 2003;23:472-481. [PubMed: 12679724]

71. Duong TQ, Kim S-G. In vivo MR measurements of regional arterial and venous blood volume fractions in intact rat brain. Magn Reson Med 2000;43:392-402.

72. Berson EL. Retinitis pigmentosa: unfolding its mystery. Proc Natl Acad Sci U S A 1996;93:45264528. [PubMed: 8643437]

73. Jones BW, Watt CB, Marc RE. Retinal remodeling. Clin Exp Optom 2005;88:282-291. [PubMed: 16255687]

74. Gal A, Li Y, Thompson DA, et al. Mutations in MERTK, the human orthologue of the RCS rat retinal dystrophy gene, cause retinitis pigmentosa. Nat Genet 2000;26:270-271. [PubMed: 11062461]

75. D'Cruz PM, Yasumura D, Weir J, et al. Mutation of the receptor tyrosine kinase gene Mertk in the retinal dystrophic RCS rat. Hum Mol Genet 2000;9:645-651. [PubMed: 10699188]

76. Mullen RJ, LaVail MM. Inherited retinal dystrophy: primary defect in pigment epithelium determined with experimental rat chimeras. Science 1976;192:799-801. [PubMed: 1265483]

77. Ball S, Hanzlicek B, Blum M, Pardue MT. Evaluation of inner retinal structure in the aged RCS rat. Adv Exp Med Biol 2003;533:181-188. [PubMed: 15180263]

78. Milam AH, Li ZY, Fariss RN. Histopathology of the human retina in retinitis pigmentosa. Prog Retin Eye Res 1998;17:175-205. [PubMed: 9695792]

79. Dowling JE, Sidman RL. Inherited retinal dystrophy in the rat. J Cell Biol 1962;14:73-109. [PubMed: 13887627]

80. Padnick-Silver L, Kang Derwent JJ, Giuliano E, Narfstrom K, Linsenmeier RA. Retinal oxygenation and oxygen metabolism in Abyssinian cats with a hereditary retinal degeneration. Invest Ophthalmol Vis Sci 2006;47:3683-3689. [PubMed: 16877443]

81. Rizzo, JFr; Wyatt, J.; Humayun, M., et al. Retinal prosthesis: an encouraging first decade with major challenges ahead. Ophthalmology 2001;108:13-14. [PubMed: 11150256]

82. Shen Q, Ren H, Bouley J, Fisher M, Duong TQ. Dynamic tracking of acute ischemic tissue fates using improved unsupervised ISODATA analysis of high-resolution quantitative perfusion and diffusion data. J Cereb Blood Flow Metab 2004;24:887-897. [PubMed: 15362719]

83. Zhang X, Li Y, Duong TQ. Image stability evaluation and motion correction for high resolution MRI of the rat retina. Proc Magn Reson Med 2009:4600. Honolulu, Hawaii. 


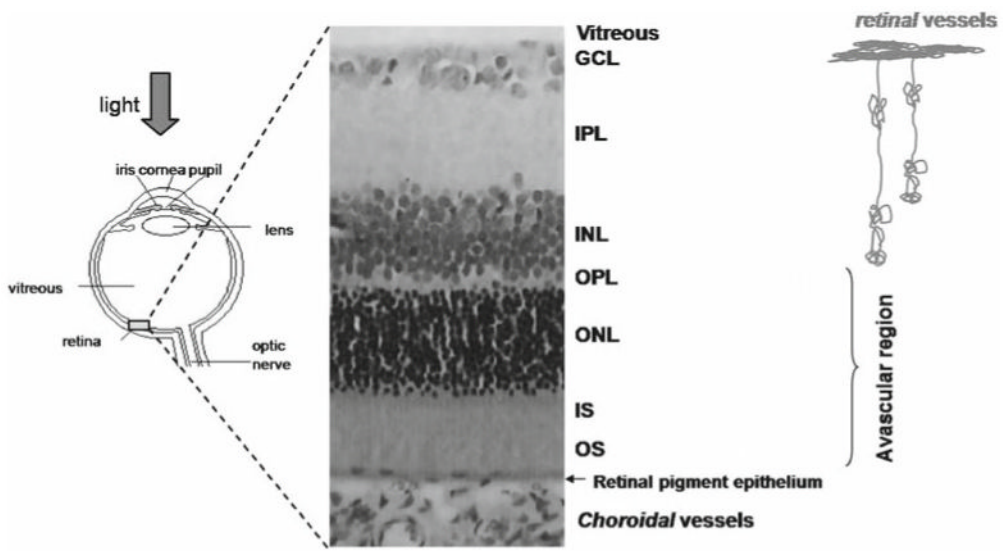

Figure 1.

Schematic drawing of the eye and histology of a rodent retina. The retina consists of multiple well-defined layers. ${ }^{1-3}$ Starting from the vitreous boundary, they include the ganglion cell layer $(G C L)$, inner plexiform layer $(I P L)$, inner nuclear layer $(I N L)$, outer plexiform layer $(O P L)$, outer nuclear layer $(O N L)$, and photoreceptor inner $(I S)$ and outer segments $(O S)$. The retina is nourished by two separate blood supplies, the retinal and choroidal circulations. The retinal vessels are within the GCL, INL, IPL, and OPL. The choroidal vessels are located posterior to the photoreceptor layer. The outer nuclear layer and the inner and outer segments are avascular. Adapted from Fig. 1 of Shen et al., J Magn Reson Imaging. ${ }^{48}$ 
(A) $1.1 \%$ isoflurane

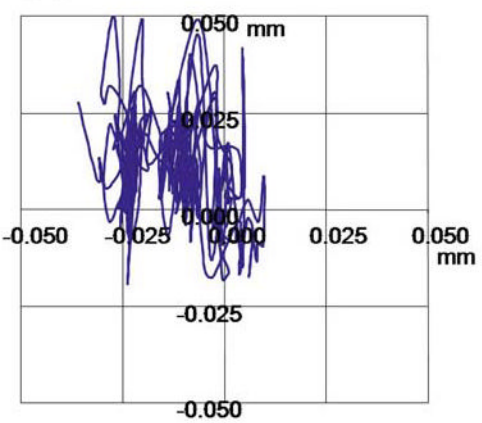

(B) $1.1 \%$ isoflurane + pancuronium

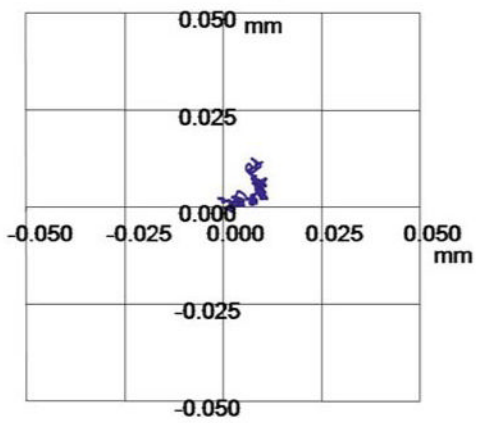

Figure 2.

A, B. Optical imaging of the corneal surface. Optical images were acquired at $7 \times 7 \mu \mathrm{m}$ on an animal under $1.1 \%$ isoflurane without $(\mathbf{A})$ and with $(\mathbf{B})$ pancuronium bromide paralytic. The traces show the in-plane displacement of a marker on the corneal surface over 4 min for both experimental conditions. Adapted from figures in Duong et al., J Magn Reson Imaging ${ }^{53}$ and Zhang et al., Proc Magn Reson Med. ${ }^{83}$ 
(A) Phase drifts

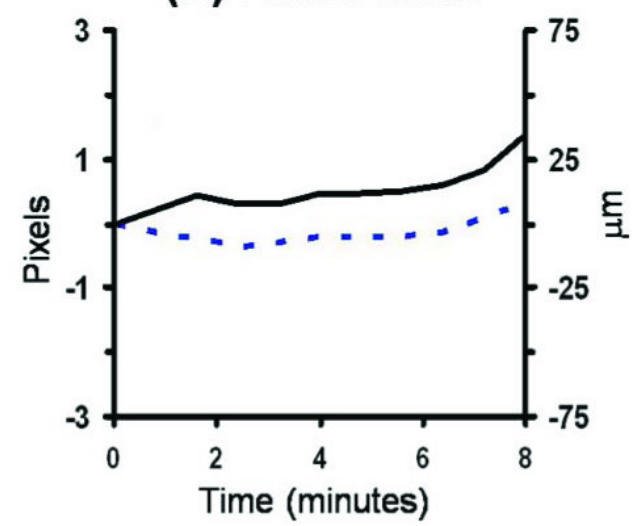

(B) Spatial profiles

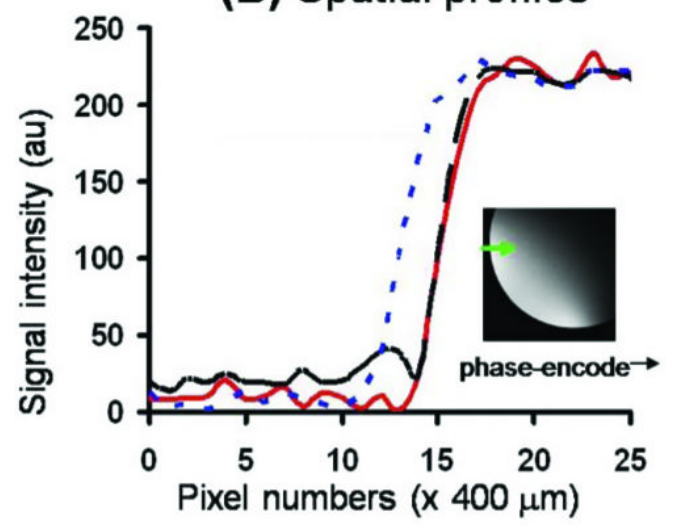

Figure 3 .

A, B. Magnetic resonance imaging (MRI) of a phantom by conventional gradient-echo MRI at $25 \times 25 \mu \mathrm{m}$. A Temporal-phase evolution in the readout (------) and phase-encode (-) direction of the entire image. B Image intensity profile of the first (-- $)$ and last (------) original images, and the last image after phase correction (-). The profiles were obtained across the phantom in the phase-encoding direction as shown in the inset. Adapted from figures in Duong et al., J Magn Reson Imaging ${ }^{53}$ and Zhang et al., Proc Magn Reson Med. ${ }^{83}$ 
(A) Phase drifts

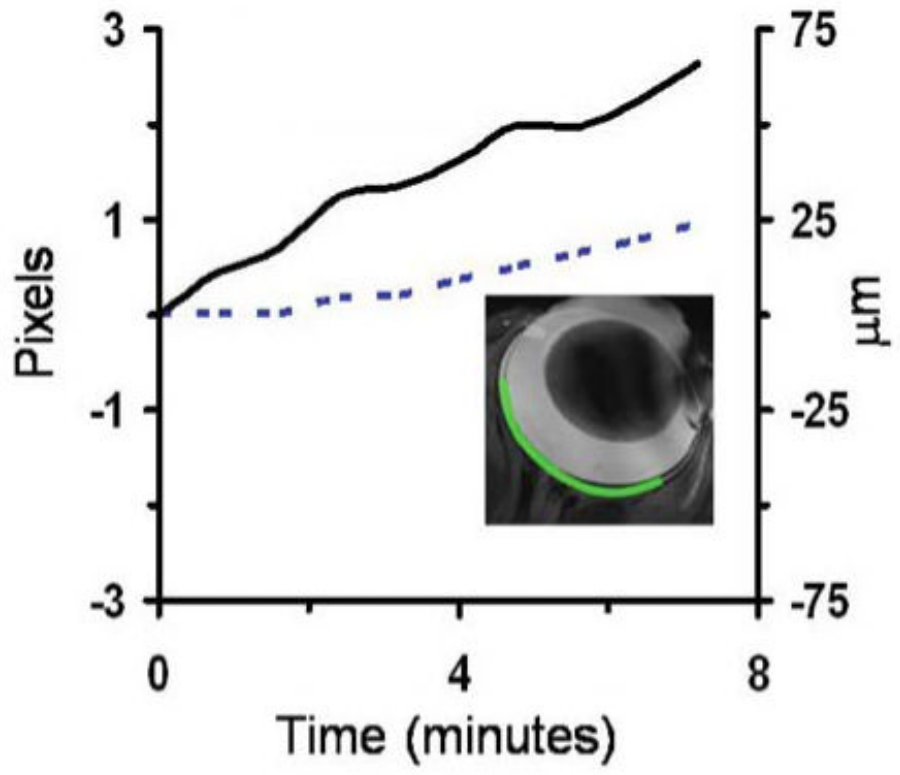

(B) Spatial profiles

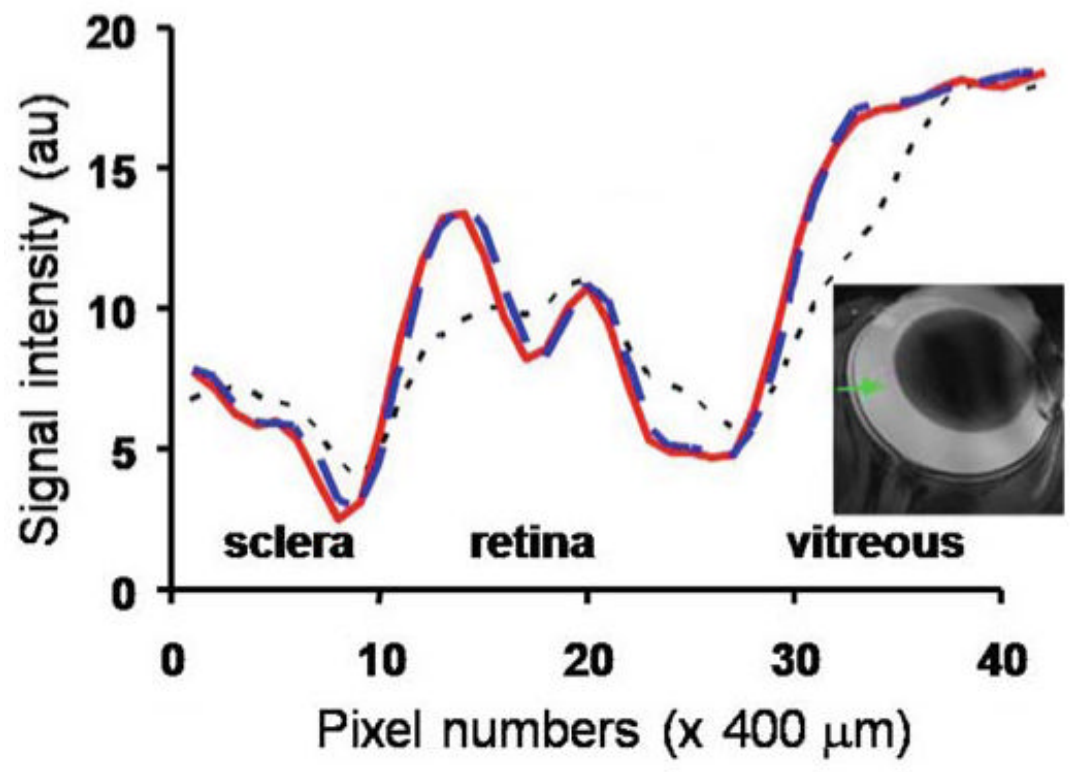

Figure 4.

A, B. In vivo MRI by conventional gradient-echo MRI at $25 \times 25 \mu \mathrm{m}$. A Temporal-phase evolution in the readout (-----) and phase-encode (-) direction of the entire retina obtained from an anesthetized and paralyzed animal using conventional gradient-echo acquisition at 25 $\times 25 \mu \mathrm{m}$. B Image intensity profiles of the in vivo original data (------), after coregistration ($--)$, and after phase correction (-) from an in vivo retina. The image profiles were obtained across the retinal thickness from the sclera to the vitreous as shown in the inset. Adapted from figures in Duong et al., J Magn Reson Imaging ${ }^{53}$ and Zhang et al., Proc Magn Reson Med. ${ }^{83}$ 
(A) Rat Retina
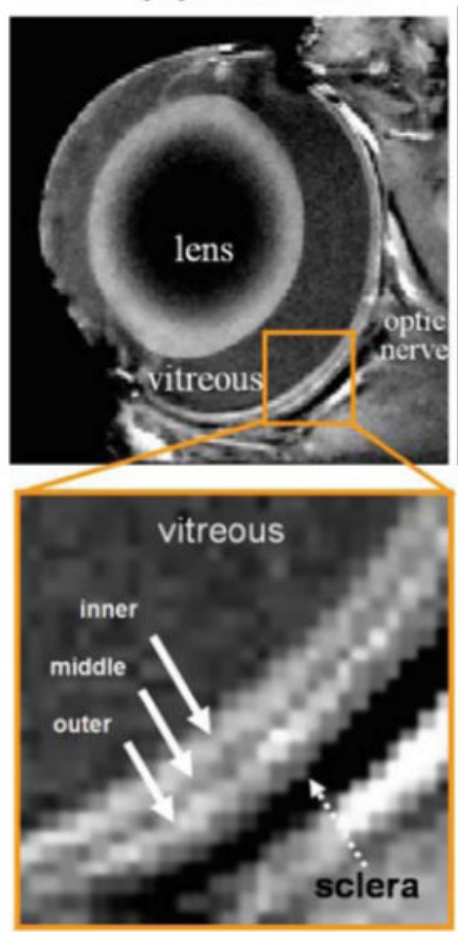

(B) Cat Retina
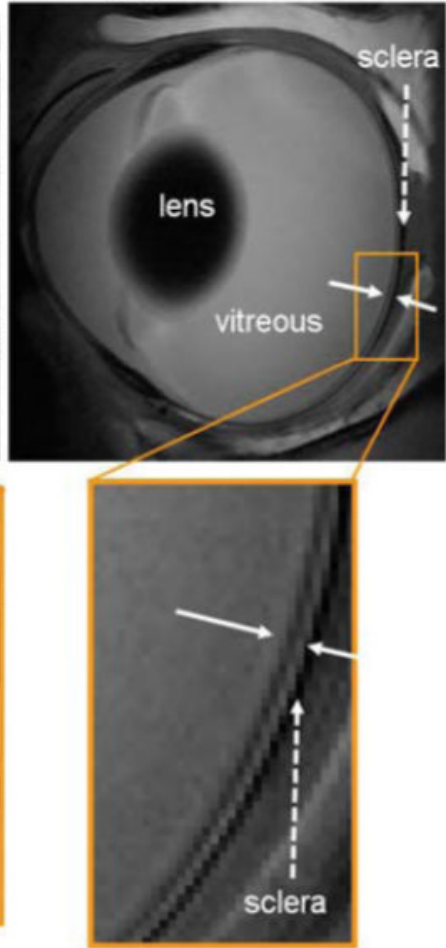

Figure 5.

A, B. Anatomical MRI of rat and cat retina. A Anatomical images from a normal SpragueDawley adult rat retina at $60 \times 60 \times 500 \mu \mathrm{m}$. Three distinct layers (solid arrows) of alternating bright, dark and bright bands are evident. The sclera (dashed arrow) is hypointense. Adapted from Fig. 1 of Cheng et al., Proc Natl Acad Sci USA. ${ }^{6}$ B Cross-sectional T2-weighted $(\mathrm{TE}=$ $40 \mathrm{~ms}$ ) images from a normal cat retina at $100 \times 100 \times 1500 \mu \mathrm{m}$ resolution. The solid white arrows indicate the inner and outer strips, respectively. The dashed arrow indicates the hypointense sclera. Adapted from Fig. 3 of Shen et al., J Magn Reson Imaging. ${ }^{48}$ 

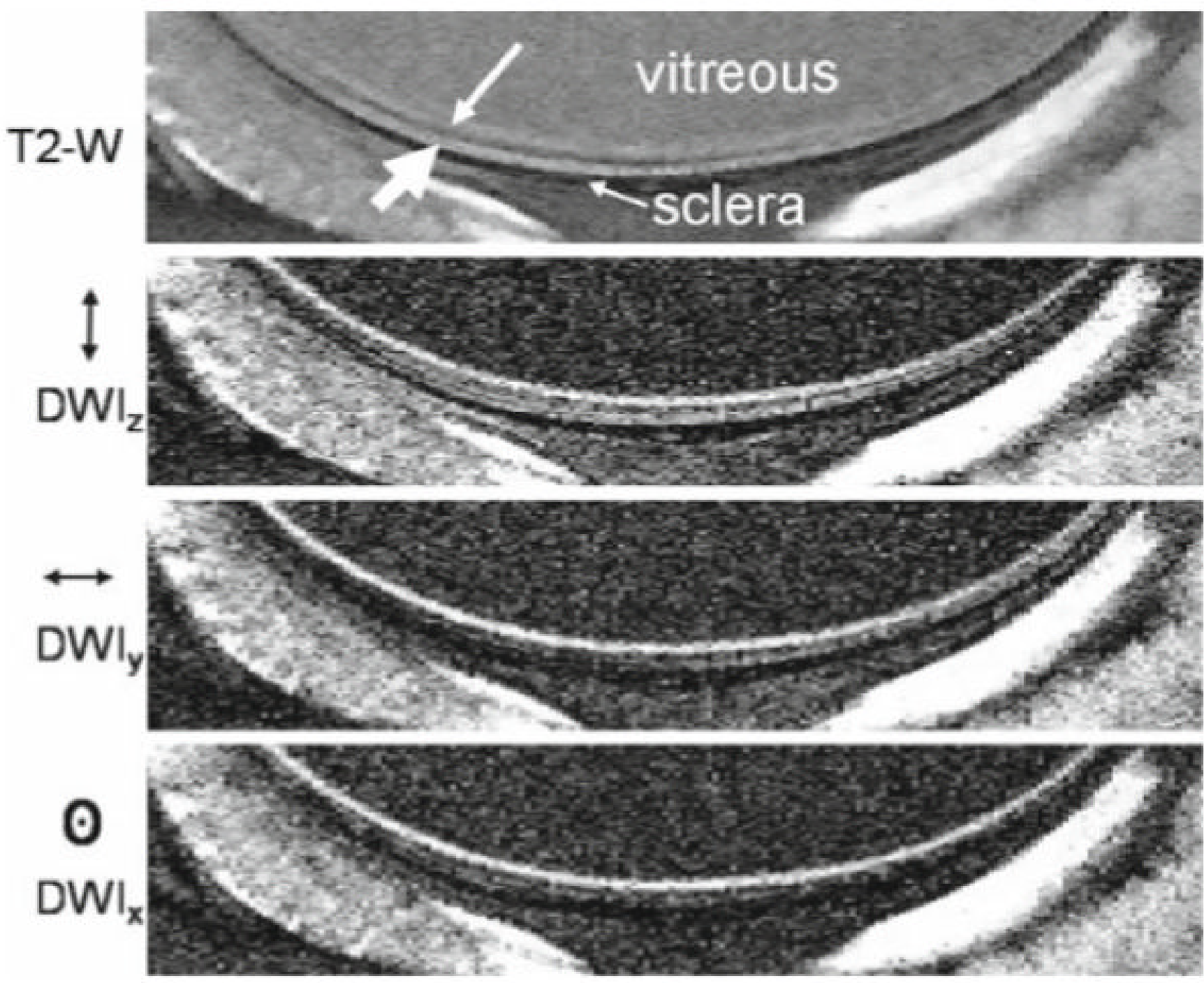

Figure 6.

Diffusion-weighted MRI of the cat retina. T2-weighted (TE $=40 \mathrm{~ms}$ ) and diffusion-weighted $\left(\mathrm{b}=504 \mathrm{~s} / \mathrm{mm}^{2}\right)$ images at $50 \times 100 \times 1500 \mu \mathrm{m}$. Diffusion-sensitizing gradients were placed along the $x, y$, or $z$ axis separately. The small and large white arrows indicate the inner and outer bands, respectively. Reproduced from Fig. 5 of Shen et al., J Magn Reson Imaging. ${ }^{48}$ 
(A) Rat retina
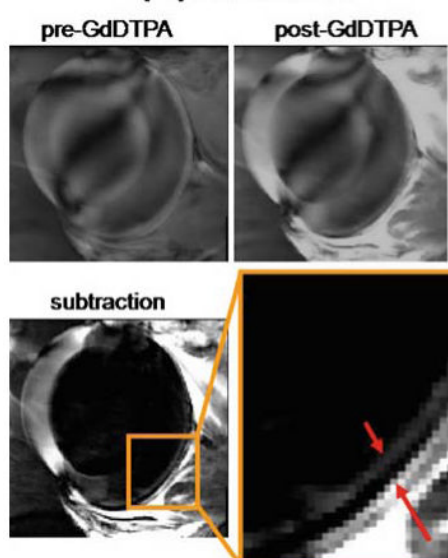

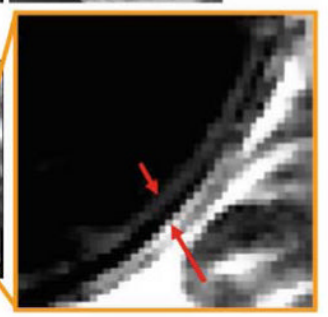

(B) Cat retina
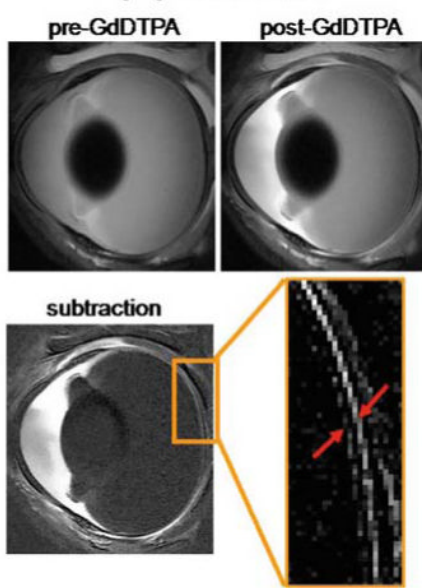

Figure 7A, B.

Gadolinium diethylenetriamine pentaacetic acid (GdDTPA)-enhanced MRI of the rat and cat retina. A Contrast-enhanced images from a normal Sprague-Dawley adult rat retina at $60 \times 60$ $\times 500 \mu \mathrm{m}$ before and after GdDTPA administration and of the subtracted image. The two arrows in the expanded view indicate the inner and outer bands of the retina corresponding to the two vascular layers bounding the retina. Signal enhancement of extraocular tissues supplied by GdDTPA permeable vessels is also present. Adapted from Fig. 2 of Cheng et al., Proc Natl Acad Sci U S A. ${ }^{6}$ B Contrast-enhanced images from a normal adult cat retina at $100 \times 100 \times$ $1500 \mu \mathrm{m}$ before and after GdDTPA administration and of the subtracted image. The two arrows in the expanded view indicate the inner and outer bands of the retina. Extraocular enhancement was also observed. Adapted from Fig. 6 of Shen et al., J Magn Reson Imaging. 48 
Rat retina

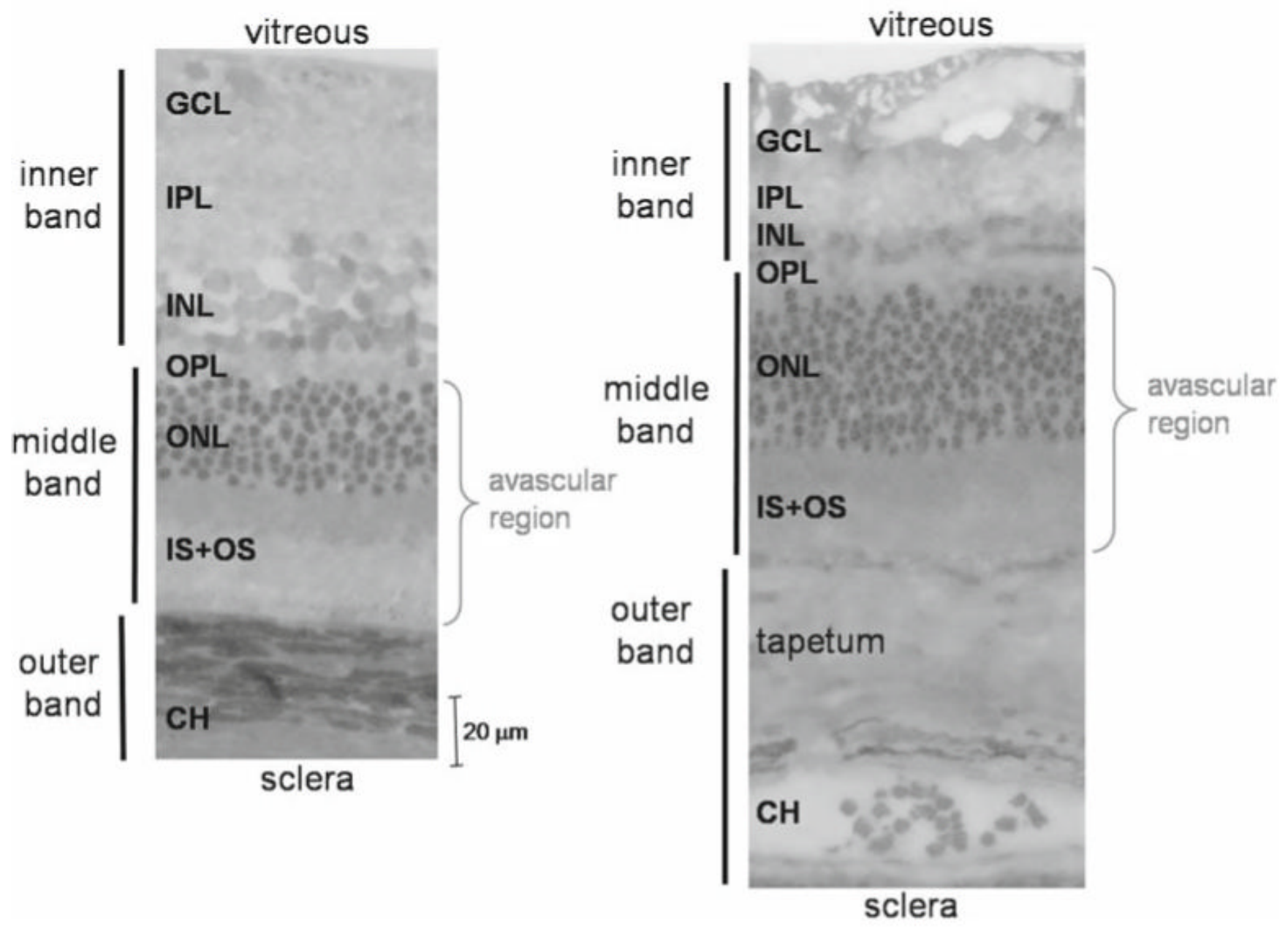

Figure 8.

Histology of the rat and cat retinas. Histological section of a normal adult Sprague-Dawley rat and cat retina stained with toluidine blue. Three vertical bars on the left show the assignments of the three MRI-derived layers. $\mathrm{CH}$, choroidal vascular layer. In the cat, there is an additional, vascularized layer known as the tapetum. The rat and cat histological slides are drawn approximately to scale. Adapted from Fig. 5 of Cheng et al, Proc Natl Acad Sci U S A, ${ }^{6}$ and Fig. 1 of Shen et al., J Magn Reson Imaging. ${ }^{48}$ 
A

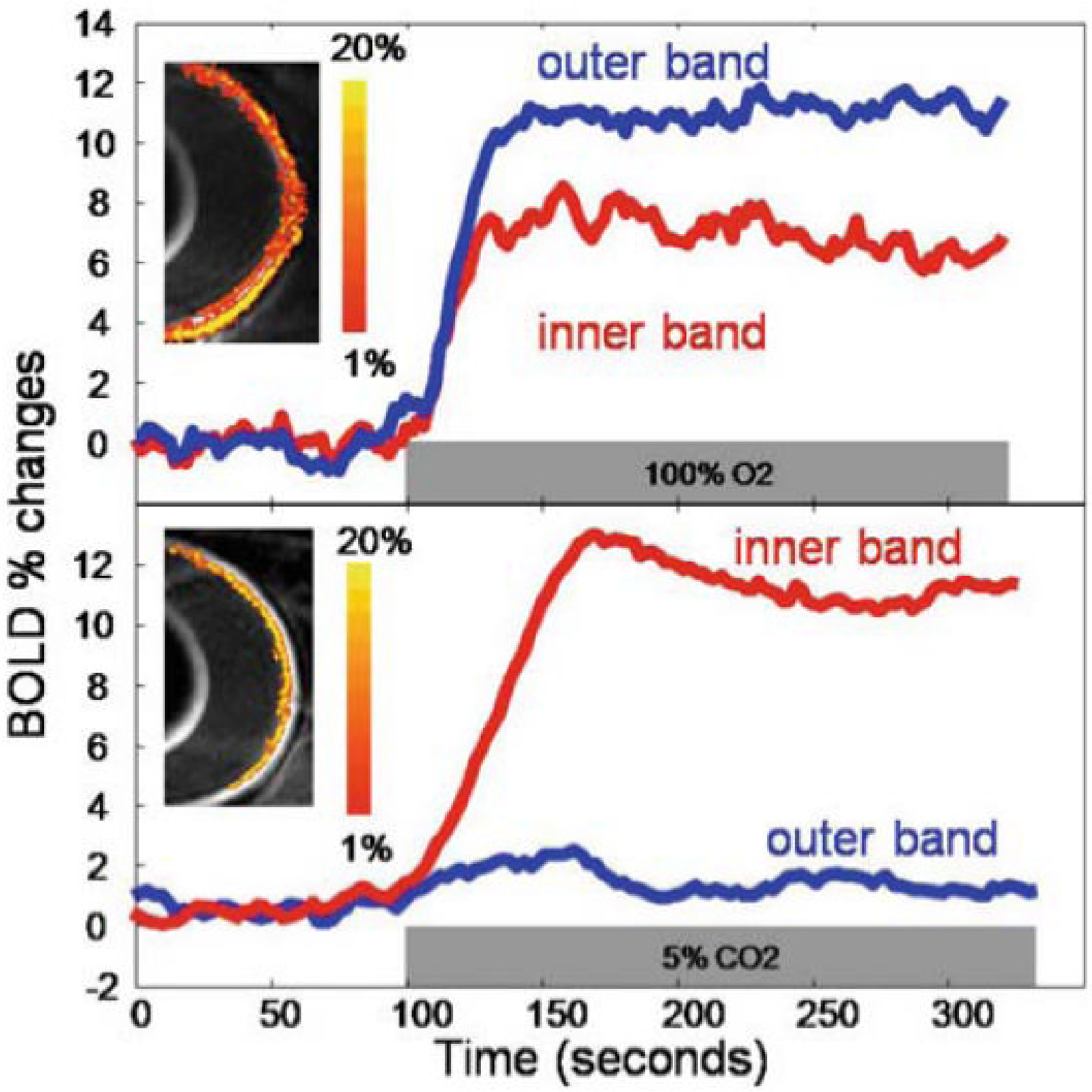

Figure 9.

A, B. Blood oxygenation level-dependent (BOLD) functional MRI (fMRI) response of the retina. Lamina-specific BOLD fMRI responses to $(\mathbf{A})$ hyperoxia $\left(100 \% \mathrm{O}_{2}\right)$ and $(\mathbf{B})$ hypercapnia $\left(5 \% \mathrm{CO}_{2}\right.$ in air) from a normal rat at $90 \times 90 \times 1000 \mu \mathrm{m}$ in-plane resolution. BOLD percent-change maps are overlaid on echo-planar images. The color bar indicates BOLD percent changes. Adapted from Fig. 6 of Cheng et al., Proc Natl Acad Sci U S A. ${ }^{6}$ 
(A) Alive

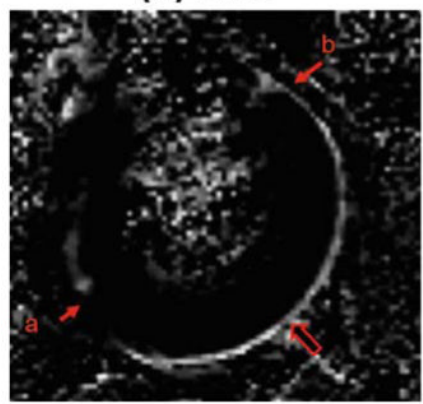

(C) Hyperoxia

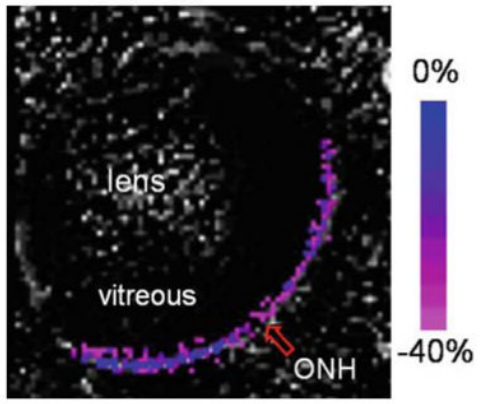

(B) Dead

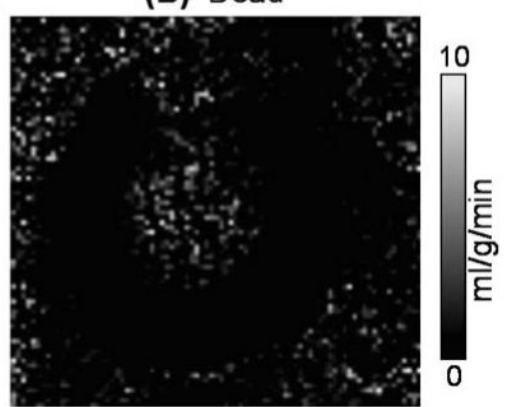

(D) Hypercapnia

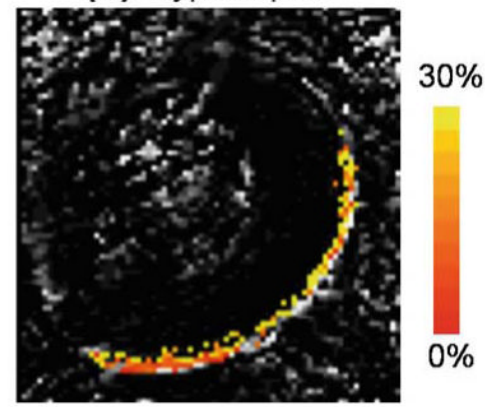

\section{Figure 10.}

A-D. Blood-flow MRI of the retina. Quantitative basal blood-flow images were obtained at $90 \times 90 \times 1000 \mu \mathrm{m}$ from a representative rat alive $(\mathbf{A})$ and dead $(\mathbf{B})$. Blood-flow values in the retina and the ciliary body are high, whereas blood flow in the lens and vitreous are within noise levels. The large arrow indicates the location of the optic nerve head $(O N H)$. Blood-flow data were obtained from one distal edge $(a)$ to the other $(b)$. Blood-flow percent-change maps responding to physiologic stimuli, (C) $100 \% \mathrm{O}_{2}$ or (D) $5 \% \mathrm{CO}_{2}$, obtained from a representative animal. Percent changes are overlaid on blood-flow maps. Color bars indicate blood-flow percent changes. Blood-flow changes due to hyperoxia and hypercapnia were statistically significantly different from baseline (air) $(P<0.05)$. Adapted from Figs. 2 and 4 of Li et al., Neuroimage. 49 
(A)

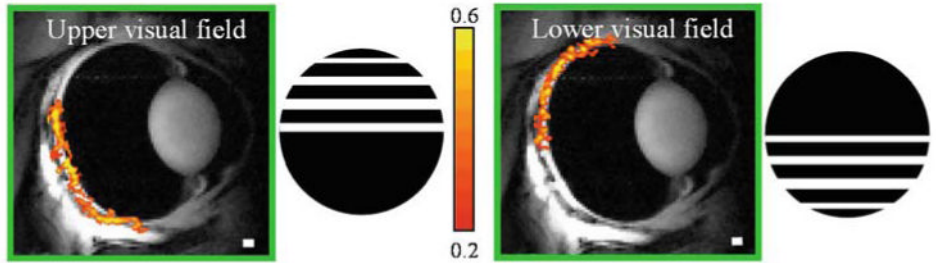

(B)

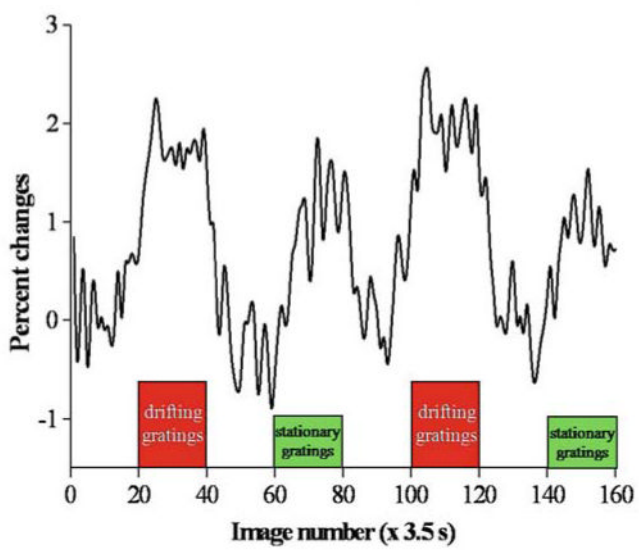

Figure 11.

A, B. fMRI of visual stimulation of the cat retina. A fMRI maps $(468 \times 468 \times 1000 \mu \mathrm{m})$ of the upper and lower visual field using drifting gratings versus dark. The gratings were a square wave with 0.15 cycles/deg and 2 cycles/s. The color bar indicates the cross-correlation coefficient. B fMRI signal modulation under dark, drifting gratings and stationary gratings (same luminance). Positive signal changes are observed under both drifting-grating and stationary-grating stimuli relative to the dark basal conditions. Signal changes due to the drifting gratings are approximately twice that of stationary gratings. Adapted from Figs. 3 and 4 of Duong et al., Invest Ophthalmol Vis Sci. ${ }^{47}$ 

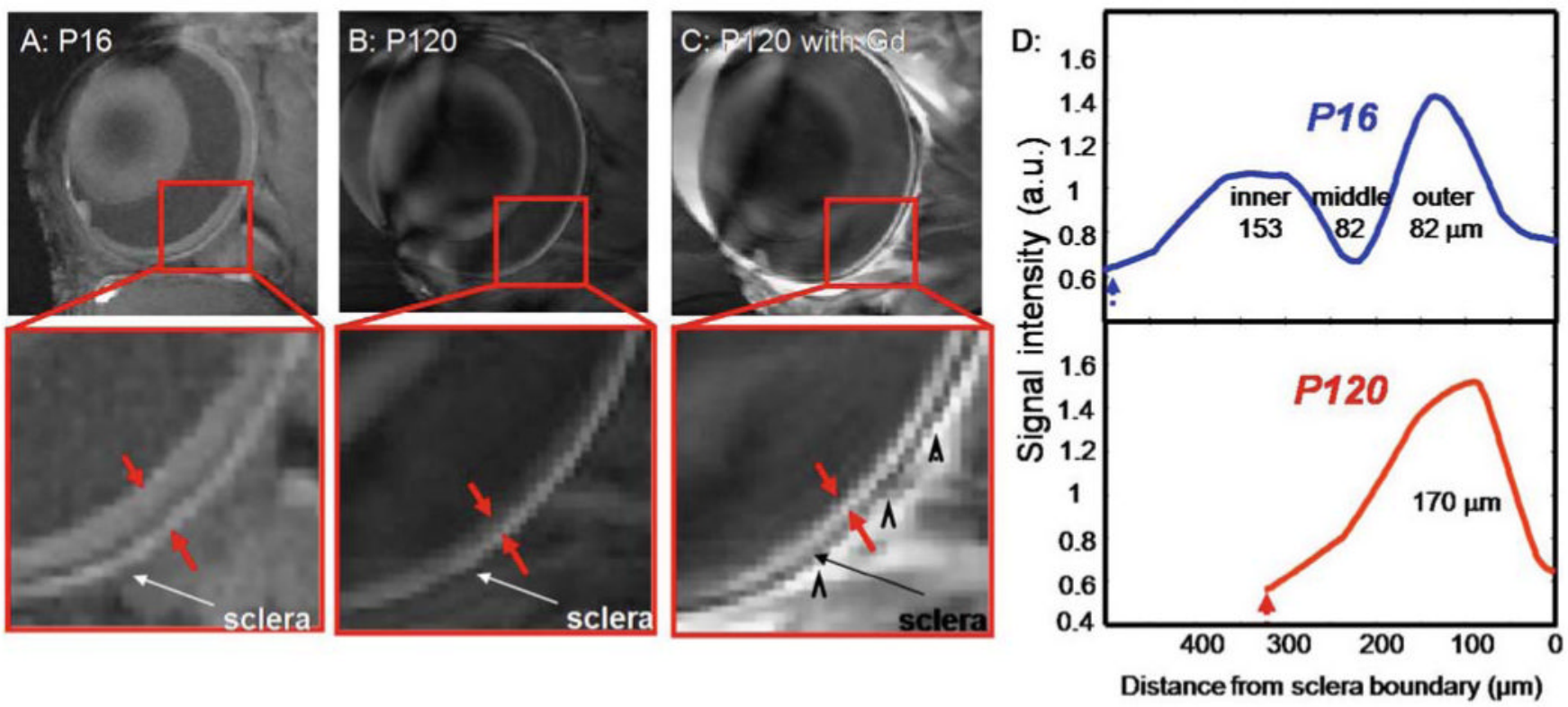

Figure 12.

A-D. Anatomical MRI of retinal degeneration in the RCS rat retina. Anatomical images at 60 $\times 60 \times 500 \mu \mathrm{m}$ of $(\mathrm{A})$ P16 RCS retina before photoreceptor degeneration, and degenerated P120 RCS retina before $(\mathbf{B})$ and after $(\mathbf{C})$ intravenous administration of Gd-DTPA. Red arrows delineate the inner and outer edges of the retina. Black arrowheads indicate signal enhancement of extraocular tissues. D Intensity profiles show thinning of the P120 compared to the P16 RCS retina. The dashed arrows indicate the vitreous boundaries. Adapted from Fig. 7 of Cheng et al., Proc Natl Acad Sci USA. ${ }^{6}$ 
(A)

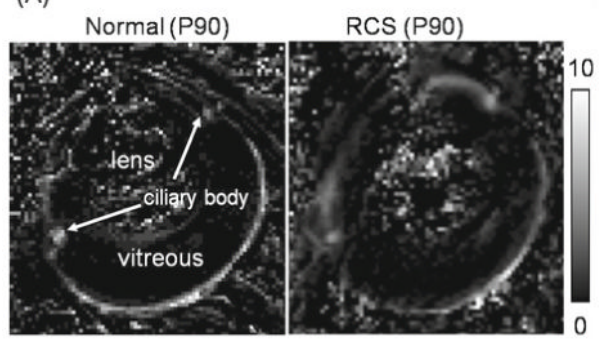

(B)

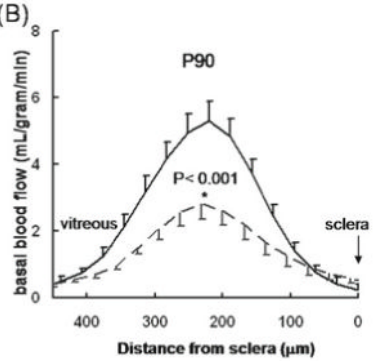

Figure 13.

A, B. Blood-flow MRI of retinal degeneration in the RCS rat retina. A Blood-flow images from a normal retina and a RCS rat retina at postnatal day 90 (P90). B Their blood-flow profiles across the retinal thickness (mean $\pm \mathrm{SD}, n=5$ ). - , normal rat; - - RCS rat. The scale bar indicates blood-flow values in $\mathrm{ml} / \mathrm{g}$ per minute. Note that the blood-flow profile of the RCS P90 rat retina was thinner than the normal retina. Adapted from Fig. 2 of Li et al., Invest Ophthalmol Vis Sci. ${ }^{50}$ 


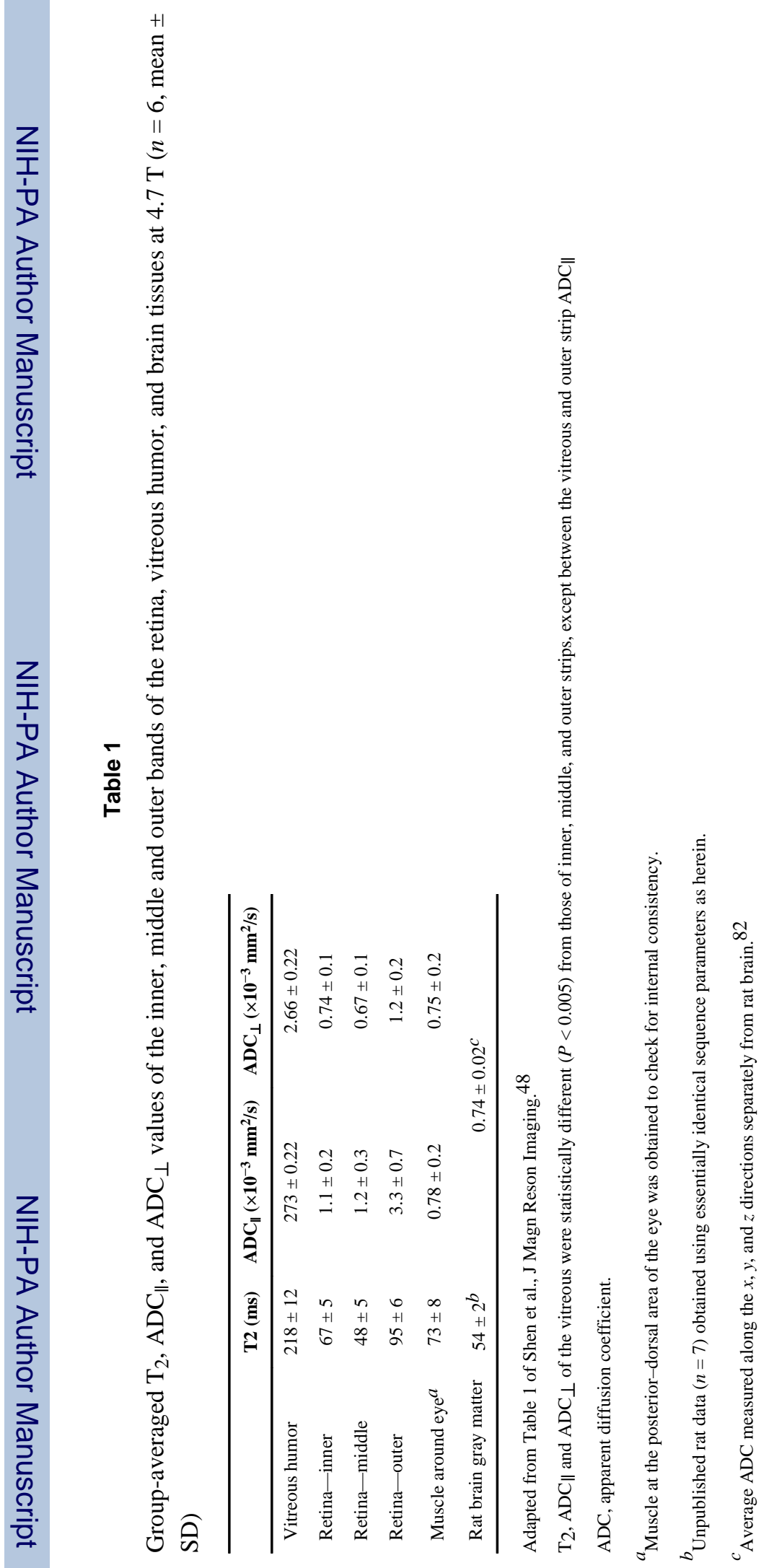

Jpn J Ophthalmol. Author manuscript; available in PMC 2010 July 9. 
Table 2

Layer thicknesses $(\mu \mathrm{m}$, mean $\pm \mathrm{SD})$ of rat retinas measured from MRI and histology

\begin{tabular}{lllll}
\hline \multicolumn{2}{l}{ Layer assignment } & & \multicolumn{2}{l}{ Layer thickness $(\boldsymbol{\mu m})$} \\
${$\cline { 1 - 1 }$} }$ & Histology & & MRI & Histology \\
\hline Inner & GCL, IPL, INL & & $101 \pm 17$ & $92 \pm 9$ \\
Middle & OPL, ONL, OS, IS & $79 \pm 17$ & $77 \pm 9$ \\
Outer & Choroid & $86 \pm 10$ & $37 \pm 8$ \\
Total & Total & $267 \pm 31$ & $205 \pm 11$ \\
\hline
\end{tabular}

MRI, magnetic resonance imaging; GCL, ganglion cell layer; IPL, inner plexiform layer; INL, inner nuclear layer; OPL, outer plexiform layer; ONL, outer nuclear layer; OS, outer segment; IS, inner segment. 


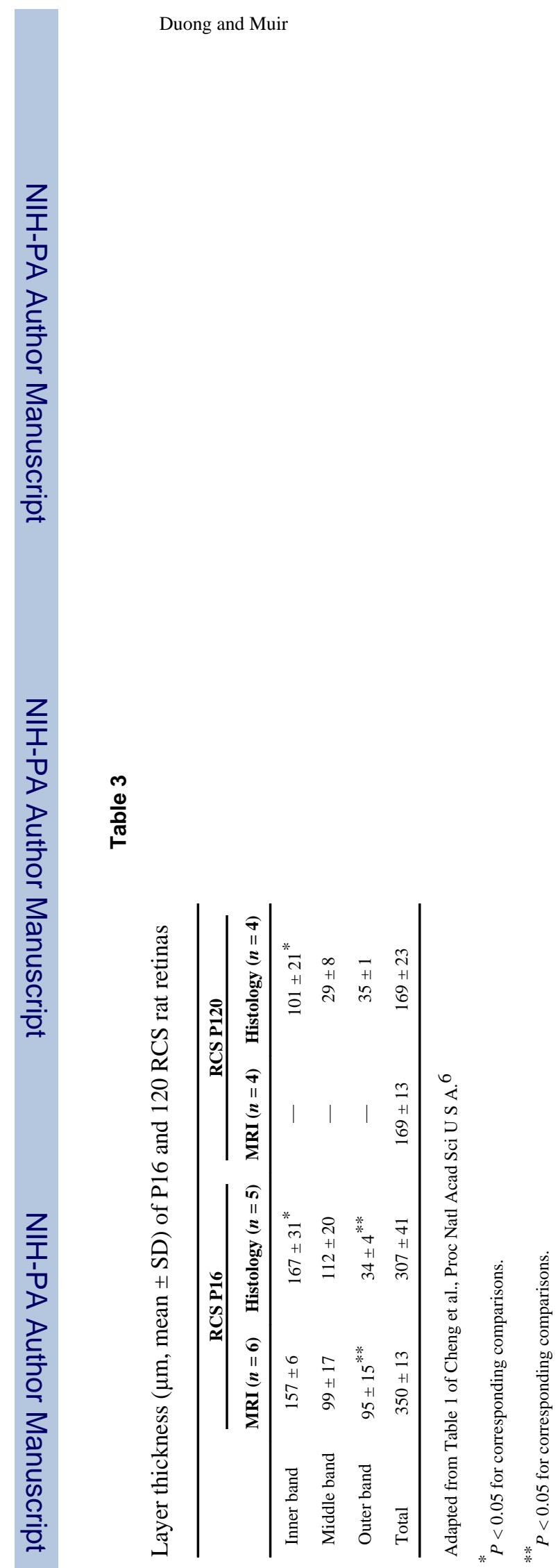

Jpn J Ophthalmol. Author manuscript; available in PMC 2010 July 9. 